\title{
Influence of Polydopamine Deposition Conditions on Hydraulic Permeability, Sieving Coefficients, Pore Size and Pore Size Distribution for a Polysulfone Ultrafiltration Membrane
}

\author{
Sirirat Kasemset ${ }^{1}$, Lu Wang ${ }^{1}$, Zhengwang He $^{1}$, Daniel J. Miller ${ }^{1, a}$, Alon Kirschner ${ }^{1}$, \\ Benny D. Freeman ${ }^{1, *}$, and Mukul M. Sharma ${ }^{2}$
}
${ }^{1}$ University of Texas at Austin, McKetta Department of Chemical Engineering, Texas Materials Institute, and Center for Energy and Environmental Resources, 10100 Burnet Road, Building 133, Austin, TX 78758, USA
${ }^{2}$ University of Texas at Austin, Department of Petroleum and Geosystems Engineering, 200 East Dean Keeton Street, Austin, TX, 78712, USA
${ }^{a}$ Current address: Joint Center for Artificial Photosynthesis, Lawrence Berkeley National Laboratory, 1 Cyclotron Road, Berkeley, CA, 94720, USA

* To whom correspondence should be addressed: freeman@che.utexas.edu (Tel: +1-512-232-2803, Fax: +1-512-232-2807)

Date: July 4, 2016

Manuscript prepared for submission to Journal of Membrane Science 


\begin{abstract}
Membrane surface modification with polydopamine (PDA) coatings can reduce fouling in oily water filtration due, at least in part, to enhanced surface hydrophilicity. In this study, polysulfone (PSf) UF membranes were coated with PDA. PDA coating conditions (solution concentration and deposition time) were varied, and the effect of coating conditions on membrane molecular weight cutoff (MWCO) and hydraulic permeability was measured. Membrane MWCO decreased and PDA film thickness increased as initial dopamine coating solution concentration or deposition time increased. The MWCO decrease confirmed that PDA restricted the membrane pores. While the PDA coating thickness on membrane surfaces grew progressively with increasing initial dopamine concentration or coating time, coating inside the membrane pores was limited by the finite membrane pore size. A tradeoff between selectivity and hydraulic permeability of unmodified and PDA-modified membranes was noted. This tradeoff is reminiscent of that observed in other separation membranes. Zydney’s hindered solute transport model of flow through porous membranes was used to estimate changes in membrane mean pore size and pore size distribution. Based on the modelling results, membrane mean pore radius increased at low initial dopamine concentrations or short deposition times and decreased at high initial dopamine concentrations or long deposition times with increasing initial dopamine concentration or increasing PDA coating time. The pore size distribution narrowed as the membranes were modified with PDA. The porosity to thickness ratio of PDA-modified membranes remained unchanged or was only slightly higher than that of unmodified membranes.
\end{abstract}




\section{Keywords:}

Surface modification, polydopamine, ultrafiltration, membrane pore size, molecular weight cutoff 


\section{INTRODUCTION}

Ultrafiltration (UF) membranes are used in many applications, such as purification and concentration of products in the food and pharmaceutical industries, drinking water production, and industrial wastewater treatment [1-3]. Membrane filtration is a promising technology for treatment of oily wastewater such as the effluent from metal working operations and produced/flowback water from oil and gas production [1-6]. UF membranes with large pores (50-200 kDa MWCO) or microfiltration (MF) membranes with relatively small pores $(\sim 0.1 \mu \mathrm{m})$ are often used in oily wastewater treatment [2].

Fouling remains a major challenge in membrane filtration. Particulates and colloidal matter in the feed deposit on membrane surfaces or inside membrane pores, and this fouling reduces membrane efficiency $[1,2,7]$. As a result of fouling, permeate flux declines when the membrane is operated in constant transmembrane pressure (TMP) mode, or TMP increases when the membrane is operated in constant permeate flux mode [1, 2, 7-9]. Fouling can result in decreased permeate water production, higher energy consumption, frequent membrane cleaning, and shorter membrane lifetime, contributing to both higher capital and operating expenses for membrane filtration $[2,8,10]$.

Membrane surface modification to increase surface hydrophilicity can reduce fouling in some circumstances $[2,9,11,12]$. Many polymeric UF and MF membranes are hydrophobic [1, 2]. Consequently, common foulants, such as oils, surfactants, and proteins, undergo favorable hydrophobic-hydrophobic interactions with the membrane surface [11]. Hydrophilic membrane surface modifications can reduce membrane-foulant hydrophobic interactions by attracting a strongly-bound water layer to the membrane surface that acts as a buffer against foulant adhesion [13].

Polydopamine (PDA) can be deposited on a wide variety of substrates from buffered, alkaline, dopamine solutions under aerobic conditions to form a thin hydrophilic layer on the 
substrate [14-18]. PDA has been applied to several types of water purification membranes to reduce fouling $[4,15-17]$. Several studies reported a decrease in pure water permeance upon coating UF membranes with PDA $[18,19]$. The pure water permeance decrease was typically ascribed to increased PDA coating thickness as well as pore size reduction or pore blockage potentially caused by PDA modification [18-22]. For porous membranes, pore size reduction or pore blockage could be major factors influencing the observed pure water permeance decrease $[1,8,23]$. Changes in membrane pore size may also influence membrane fouling behavior [2, 15].

This study explores changes in polysulfone (PSf) UF membrane pore size and pore size distribution due to PDA modification at various deposition conditions because a detailed investigation of PDA surface modification on pore size and pore size distribution has never been reported. Such studies are of interest since surface modification of porous membranes may influence both fouling properties and sieving properties, and the effect of PDA modification on sieving properties has not been systemically studied. To characterize PDA coating thickness on PSf surfaces, ellipsometry was used to measure the thickness of PDA coatings deposited on dense PSf films at various coating conditions. Changes in nominal membrane pore size due to PDA deposition were estimated using molecular weight cutoff (MWCO) measurements on unmodified and PDA-modified UF membranes. PDA coating thickness on membrane surfaces was compared to that inside membrane pores. The pure water permeance of unmodified and PDA-modified membranes was measured. A tradeoff between membrane selectivity and permeability was observed. Model calculations were used to estimate the effect of PDA modifications on membrane mean pore size and pore size distribution. 


\section{THEORETICAL BACKGROUND}

\subsection{Membrane Hydraulic Permeability}

Hydraulic permeability of porous membranes is often based on idealized models assuming fluid flow through cylindrical pores using the Hagen-Poiseuille equation. The average hydraulic permeability, based on a distribution of cylindrical pores with varying pore sizes, is $[24,25]:$

$$
\bar{L}_{p}=\frac{\varepsilon}{8 \mu \delta_{m}} \frac{\int_{0}^{\infty} n(r) r^{4} d r}{\int_{0}^{\infty} n(r) r^{2} d r}
$$

where $\bar{L}_{p}$ is the average membrane hydraulic permeability, $\varepsilon$ is the membrane porosity, $\mu$ is the solvent viscosity (water in this study, so $\mu \approx 9 \times 10^{-4} \mathrm{~kg} /(\mathrm{m} \cdot \mathrm{s})$ at $25^{\circ} \mathrm{C}$ [26]), $\delta_{m}$ is the membrane selective layer thickness, $r$ is the membrane pore radius, and $n(r)$ describes the pore size distribution. The factor $\varepsilon / \delta_{m}$ should also be viewed as accounting for any deviation of pores from straight cylinders (i.e., tortuosity effects).

The average membrane hydraulic permeability can be calculated from experimental data as follows:

$$
\bar{L}_{p}=\frac{\bar{J}_{p w}}{T M P_{n}}
$$

where $\bar{J}_{p w}$ is the average steady state pure water flux (i.e., pure water volumetric flow rate per unit area), and $T M P_{n}$ is the nominal measured transmembrane pressure during pure water filtration, which represents the average transmembrane pressure experienced by the membrane filtration area.

A log-normal pore size distribution is often used for UF membranes [24, 27]:

$$
n(r)=\frac{n_{o}}{r} \times \frac{1}{\sqrt{2 \pi \ln \left(1+(\sigma / \bar{r})^{2}\right)}} \times \exp \left\{-[\ln (r / \bar{r})]^{2} \times\left[\frac{1+(\sigma / \bar{r})^{2}}{2 \ln \left[1+(\sigma / \bar{r})^{2}\right]}\right]\right\}
$$

where $n(r)$ is the number of pores of radius $r$ per unit area, $n_{o}$ is the total number of pores per unit area, $\bar{r}$ is the mean pore size, and $\sigma$ is the standard deviation of the log-normal distribution. In 
subsequent calculations involving Equation (1), $n_{o}$ always appears in both the numerator and

denominator, so it cancels. Based on this model, $\bar{L}_{p}$ depends on three parameters: $\bar{r}, \sigma / \bar{r}$, and $\varepsilon / \delta_{m}$. However, these parameters cannot be determined directly from Equation (1) using only pure water permeance data. Using the log-normal pore size distribution and the measured hydraulic permeability (i.e., pure water permeance), the ratio of porosity to selective layer thickness, $\varepsilon / \delta_{m}$, may be calculated from the following rearranged form of Equation (1) if $\bar{r}$ and $\sigma$ are known:

$$
\frac{\varepsilon}{\delta_{m}}=8 \mu \bar{L}_{p} \frac{\int_{0}^{\infty} n(r) r^{2} d r}{\int_{0}^{\infty} n(r) r^{4} d r}=8 \mu \bar{L}_{p}\left(\frac{\left(1+(\sigma / \bar{r})^{2}\right)^{\left.-\frac{6}{1+(\sigma / r}\right)^{2}}}{\bar{r}^{2}}\right)
$$

Other models, including a model for hindered solute transport through membrane pores and a concentration polarization model, can be used with Equation (4) and experimental water and solute transport data to estimate values of $\bar{r}, \sigma / \bar{r}$, and $\varepsilon / \delta_{m}$.

\subsection{Solute Mass Transport Near and Through Membranes}

As shown in Figure 1(a), during ultrafiltration in a stirred cell, solutes in the feed solution either partially or completely rejected by the membrane accumulate at the membrane surface, forming a concentration boundary layer where the solute concentration is higher than that in the bulk feed solution [8]. The concentration boundary layer thickness, $\delta_{c}\left(r_{c}\right)$, depends on radial position in the stirred cell and develops from the outer edge towards the central axis of the stirred cell [28]. From a mass balance based on convective and diffusive solute transport in the concentration boundary layer, the mass transfer coefficient, $k$, relates permeate flux, $J_{v}$, and solute concentration driving force as follows [8, 29]:

$$
J_{v}=k \ln \left(\frac{C_{m}-C_{f}}{C_{b}-C_{f}}\right)
$$

Generally, the permeate flux is proportional to the transmembrane pressure, TMP, across the membrane. In a stirred cell, the feed pressure at the membrane surface, $P_{\text {feed }}\left(r_{c}\right)$, can vary 
radially in the stirred cell, as shown in Figure 1(b), due to fluid rotation. In a laboratory MWCO measurement, an overhead stirrer, operating at a rotation rate of $\omega$, causes the fluid to rotate. Thus, the permeate flux, $J_{v}\left(r_{c}\right)$, may vary radially. As solutes transport from the bulk feed solution to the permeate, they pass through the concentration boundary layer and then the membrane pores. The solute transport mechanism through each of these resistances (i.e., concentration boundary layer and membrane pores) can be described using models containing $\bar{r}$, $\sigma / \bar{r}$, and $\varepsilon / \delta_{m}$. In this study, these models are used together with the Hagen-Poiseuille equation (i.e., Equation (4)) and experimental pure water permeance and solute sieving data to estimate values of $\bar{r}, \sigma / \bar{r}$, and $\varepsilon / \delta_{m}$ as a function of membrane modification conditions.
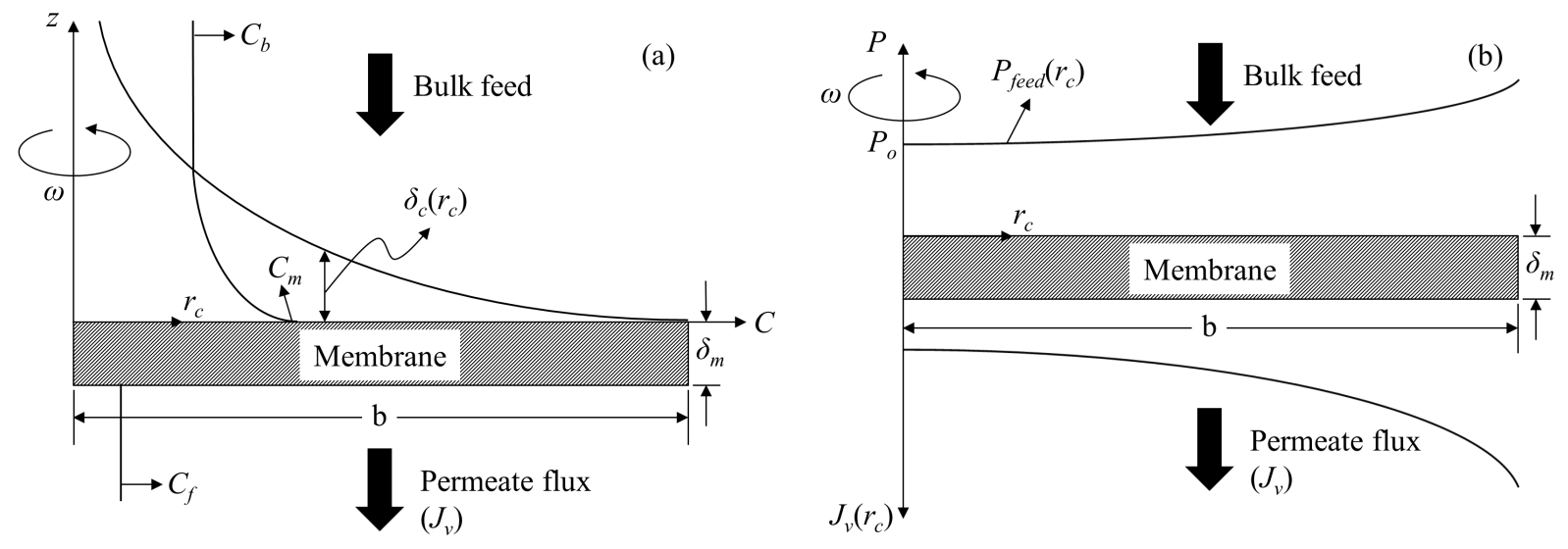

Figure 1. (a) Concentration and concentration boundary layer thickness profiles of partially or completely rejected solutes during ultrafiltration in a stirred cell. $z$ represents the vertical distance from the membrane surface, $r_{c}$ represents the radial distance from the center of the stirred cell, $\delta_{c}\left(r_{c}\right)$ is the concentration boundary layer thickness, $\delta_{m}$ is the membrane selective layer thickness, $b$ is the membrane radius, $C_{f}$ is the filtrate solute concentration, $C_{b}$ is the bulk feed solute concentration, and $C_{m}$ is the solute concentration on the feed side of the membrane surface. $\omega$ is the stirring speed in the stirred cell. (b) Radial dependence of feed pressure $\left(P_{\text {feed }}\left(r_{c}\right)\right)$ and permeate flux $\left(J_{v}\left(r_{c}\right)\right)$ in the stirred cell. $P_{o}$ is the feed pressure at the central axis of the stirred cell at the membrane surface. The filtrate feed pressure is $P_{f}$, which is assumed to be independent of $r_{c}$. The local transmembrane pressure, TMP local $\left(r_{c}\right)$, is defined as $P_{f e e d}\left(r_{c}\right)-P_{f}$. 


\subsubsection{Concentration Polarization}

Solute transport through porous membranes is often described in terms of an actual sieving coefficient, $S_{a}$, or an actual retention coefficient, $R_{a} . S_{a}$ is the ratio of $C_{f}$ to $C_{m}$, and $S_{a}$ is related to $R_{a}$ as follows [8, 30]:

$$
S_{a}=1-R_{a}=\left(\frac{C_{f}}{C_{m}}\right)
$$

Since solute concentration in the boundary layer is higher than in the bulk feed, concentration polarization causes the actual sieving coefficient to be lower than the observed sieving coefficient $[8,30]$. The observed sieving coefficient, $S_{o}$, and observed retention coefficient, $R_{o}$, are defined based on measurable, bulk solute concentrations in the bulk feed and filtrate, $C_{b}$ and $C_{f}$, as follows $[8,31]$ :

$$
S_{o}=1-R_{o}=\left(\frac{C_{f}}{C_{b}}\right)
$$

The observed sieving coefficient is measured in solute filtration experiments. However, the actual sieving coefficient typically cannot be measured directly because the solute concentration at the membrane surface (i.e., $C_{m}$ ) is not known. A mass transfer model, developed based on Equations (5) - (7), is employed to relate $S_{a}$ to $S_{o}$. The stagnant film model for this purpose is [8, 30]:

$$
S_{o}=\frac{S_{a}}{\left(1-S_{a}\right) \exp \left(-\frac{\bar{J}_{v}}{\bar{k}}\right)+S_{a}}
$$

where $\bar{J}_{V}$ is the measured average permeate flux, and $\bar{k}$ is the average mass transfer coefficient in the concentration boundary layer. A mass transfer coefficient model, presented later, is used to calculate $\bar{k}$. Alternatively, $S_{a}$ in Equation (8) can be estimated using a hindered solute transport model as discussed in the next section. This model can be used to calculate $S_{a}$ and, in turn, $S_{o}$, which can then be compared with experimental values of $S_{o}$. 


\subsubsection{Solute Transport through Porous Membranes}

Solute transport through a membrane occurs due to both convection and diffusion. A hydrodynamic model describing solute transport through porous membranes based on hindered convection and diffusion was reported by Opong and Zydney [30]. This model calculates $S_{a}$ as a function of the ratio of solute size to membrane pore size and the hydrodynamic conditions of solute transport, which are characterized by the Peclet number inside the membrane pores, $P e_{m}$. The actual sieving coefficient of a membrane of pore radius $r$ and a solute of radius $a$ at radial position $r_{c}$ in the stirred cell, $S_{a}\left(r, a, r_{c}\right)$, is given by the following expression [8, 28, 30]:

$$
S_{a}\left(r, a, r_{c}\right)=\frac{S_{\infty}(r, a) \exp \left[P e_{m}\left(r, a, r_{c}\right)\right]}{S_{\infty}(r, a)+\exp \left[P e_{m}\left(r, a, r_{c}\right)\right]-1}
$$

where $S_{\infty}(r, a)$ is the so-called asymptotic sieving coefficient, and $P e_{m}\left(r, a, r_{c}\right)$ is the Peclet number in a pore of radius $r$. $P e_{m}$ depends sensitively on permeate flux, solute diffusivity, and membrane properties (i.e., $\left.\varepsilon / \delta_{m}\right) . P e_{m}$ is given by [28, 30]:

$$
P e_{m}\left(r, a, r_{c}\right)=\left(\frac{S_{\infty}(r, a)}{\phi(r, a) K_{d}(r, a)}\right)\left(\frac{J_{v}\left(r_{c}\right) \delta_{m}}{D_{\infty} \varepsilon}\right)=\left(\frac{K_{c}(r, a)}{K_{d}(r, a)}\right)\left(\frac{J_{v}\left(r_{c}\right) \delta_{m}}{D_{\infty} \varepsilon}\right)
$$

where $\phi(r, a)$ is the equilibrium partition coefficient of the solute between the fluid in the membrane pore and the fluid adjacent to the membrane. $\varepsilon / \delta_{m}$ can be set as a constant [24] or estimated from the rearranged form of the Hagen-Poiseuille equation, Equation (4). $D_{\infty}$ is the solute diffusion coefficient at infinite dilute solution. For poly(ethylene glycol) (PEG) in water at $25^{\circ} \mathrm{C}, D_{\infty}$ is calculated as follows [32, 33]:

$$
D_{\infty}=1.465 \times 10^{-8}\left(M^{-0.557}\right)
$$

where $D_{\infty}$ has units of $\mathrm{m}^{2} / \mathrm{s}$, and $M$ is the PEG molecular weight (as specified by the manufacturer) in $\mathrm{g} / \mathrm{mol}$.

$$
K_{c}(r, a) \text { and } K_{d}(r, a) \text { are hindrance factors for solute convection and diffusion, }
$$
respectively, and they depend on the ratio of solute radius to membrane pore radius [30]. Algebraic expressions for them are given in the supplementary information. The asymptotic 
sieving coefficient, $S_{\infty}(r, a)$, is $S_{a}$ at very large permeate flux values [28] and can be calculated from Equation (12):

$$
S_{\infty}(r, a)=\phi(r, a) K_{c}(r, a)
$$

For a spherical solute in a cylindrical pore, $\phi(r, a)$ is given by [28, 30]:

$$
\phi(r, a)=\left[1-\left(\frac{a}{r}\right)\right]^{2}
$$

where $r$ is the membrane pore radius. $a$ is the solute radius, which can be estimated from Stokes radius of the solute. The Stokes radius of PEG can be estimated as follows [34]:

$$
a=16.73 \times 10^{-12} M^{0.557}
$$

where $a$ is the Stokes radius of PEG (m), and $M$ is the PEG molecular weight (as specified by the manufacturer) (g/mol).

In some cases (e.g., large diameter membrane test cells), permeate flux could vary with radial position in the stirred cell due to the radial pressure gradient which naturally develops due to the fluid rotation depicted in Figure 1(b). In this case, the local permeate flux would be given by [35]:

$$
J_{v}\left(r_{c}\right)=\bar{L}_{p} \times T M P_{\text {local }}\left(r_{c}\right)=\bar{L}_{p} \times\left[P_{\text {feed }}\left(r_{c}\right)-P_{f}\right]=\bar{L}_{p} \times\left[P_{o}+\frac{1}{2} \rho \omega^{2} r_{c}^{2}-P_{f}\right]
$$

where $T M P_{\text {local }}\left(r_{c}\right)$ is the local transmembrane pressure at a particular radial position $r_{c}$ in the stirred cell. $P_{\text {feed }}\left(r_{c}\right)$ is the applied feed pressure at a radial position $r_{c}$ at the membrane surface, $P_{o}$ is the applied feed pressure at the central axis (i.e., $r_{c}=0$ ) at the membrane surface, and $P_{f}$ is the filtrate pressure. $P_{o}-P_{f}$ is constant during the filtration. In MWCO experiments, the average permeate flux, $\bar{J}_{v}$, is fixed in the experiments. Since $P_{o}$ is not measured directly from the experiments, the value of $P_{o}-P_{f}$ is determined from the average permeate flux, $\bar{J}_{v}$, measured during a solute filtration experiment:

$$
\bar{J}_{v}=\frac{\int J_{v}\left(r_{c}\right) d A}{\int d A}=\bar{L}_{p} \times\left[\left(P_{o}-P_{f}\right)+\frac{1}{4} \rho \omega^{2} b^{2}\right]
$$


where $A$ is the effective membrane filtration area. Combining Equations (15) and (16), and eliminating $P_{o}-P_{f}$ yields:

$$
J_{v}\left(r_{c}\right)=\bar{J}_{v}+\left[\frac{1}{4} \bar{L}_{p} \rho \omega^{2} \times\left(2 r_{c}^{2}-b^{2}\right)\right]
$$

In this study, membrane pure water permeance, determined experimentally, was used for $\bar{L}_{p}$. In many cases, the variation of permeate flux with radial position is very minor even in rather large diameter laboratory test cells. When the dependence of $J_{v}$ on $r_{c}$ is not significant, $\bar{J}_{v}$ can be used instead of $J_{v}\left(r_{c}\right)$ in Equation (10) to calculate $P e_{m}$ once the remaining parameters in Equation (10) $\left(r, a, D_{\infty}\right.$, and $\left.\varepsilon / \delta_{m}\right)$ are established. Then, $S_{a}(r, a)$ can be calculated using Equation (9).

The average actual sieving coefficient for a solute of radius $a$ at radial position $r_{c}$ in the stirred cell, $\bar{S}_{a}\left(a, r_{c}\right)$, can be calculated by summing the contributions to $S_{a}$ from all pores in the membrane that are capable of permeating the solute of interest (i.e., all pores whose radius, $r$, is greater than the radius of the solute particle, $a$ ) [24, 28]:

$$
\bar{S}_{a}\left(a, r_{c}\right)=\frac{\int_{a}^{\infty} S_{a}\left(r, a, r_{c}\right) n(r) r^{4} d r}{\int_{0}^{\infty} n(r) r^{4} d r}
$$

If permeate flux does not vary significantly with radial position, $\bar{S}_{a}$ depends only on $a$ (i.e., $\bar{S}_{a}\left(a, r_{c}\right)$ becomes $\left.\bar{S}_{a}(a)\right)$. In this case, $S_{o}$ can be estimated by substituting this $\bar{S}_{a}(a)$ for $S_{a}$ in Equation (8).

\subsubsection{Mass Transfer Coefficient Determination}

For laminar flow $(R e<32,000)$ in a stirred cell, the average mass transfer coefficient, $\bar{k}$, is $[8,30]$ :

$$
\bar{k}=\alpha_{\text {stir }} R e^{0.567} S c^{1 / 3}\left(\frac{D_{\infty}}{b}\right)
$$

where $R e$ is the Reynolds number $\left(=\omega b^{2} / v\right), S c$ is the Schmidt number $\left(=v / D_{\infty}\right), b$ is the membrane radius determined from the effective membrane filtration area, $\omega$ is the stirring speed 
(radians/s), and $v$ is the kinematic viscosity of the solution. In this work, $v$ is taken to be that of pure water $\left(v \approx \mu_{\text {water }} / \rho_{\text {water }} \approx 9 \times 10^{-7} \mathrm{~m}^{2} / \mathrm{s}, \mu_{\text {water }} \approx 9 \times 10^{-4} \mathrm{~kg} /(\mathrm{m} \cdot \mathrm{s})\right.$, and $\rho_{\text {water }} \approx 997 \mathrm{~kg} / \mathrm{m}^{3}$ at $25^{\circ} \mathrm{C}$ [26]) due to the dilute concentration of the solute solutions. $\alpha_{\text {stir }}$ is a constant based on the filtration device geometry. An $\alpha_{\text {stir }}$ value of 0.23 was reported by Opong and Zydney for a stirred cell $[8,30]$, and this value was used in Equation (19) in this study. This $\alpha_{\text {stir }}$ value is very close to the value $\left(\alpha_{\text {stir }}=0.25\right)$ calculated from the correlation proposed by Smith et al. [36].

In practice, the concentration boundary layer thickness, $\delta_{c}$ varies with radial position in the stirred cell, $r_{c}$. Therefore, the mass transfer coefficient $\left(k=\frac{D_{\infty}}{\delta_{c}\left(r_{c}\right)}\right.$ [31]) also varies with radial position. Zydney and Xenopoulos used the following model for the local mass transfer coefficient in a stirred cell [28]:

$$
k\left(r_{c}\right)=\alpha_{\text {stir }} R e^{0.567} S c^{1 / 3}\left(\frac{D_{\infty}}{b}\right) \frac{r_{c}}{\left(b^{3}-r_{c}^{3}\right)^{1 / 3}}
$$

An $\alpha_{\text {stir }}$ value of 0.23 was also used in Equation (20) in our study.

If the local mass transfer coefficient, $k\left(r_{c}\right)$, and the local permeate flux, $J_{v}\left(r_{c}\right)$, are used in the analysis (rather than $\bar{k}$ and $\bar{J}_{v}$ ), the expression for the observed sieving coefficient (i.e., Equation (8)) is replaced by the following analog, which accounts for the radial dependence of the mass transfer coefficient and filtration flux [28]:

$$
S_{o}=\frac{C_{f}}{C_{b}}=\frac{1}{\int J_{v}\left(r_{c}\right) d A} \int\left[J_{v}\left(r_{c}\right) \frac{S_{a}}{\left(1-S_{a}\right) \exp \left[-\frac{J_{v}\left(r_{c}\right)}{k\left(r_{c}\right)}\right]+S_{a}}\right] d A
$$

where $C_{f}$ is the mixing cup average filtrate composition (i.e., the filtration composition that would be collected during an experiment). In this case, $\bar{S}_{a}\left(a, r_{c}\right)$ estimated from Equation (18) is used for $S_{a}$ in Equation (21). 


\subsection{Data Fitting to Determine $\bar{r}, \sigma / \bar{r}$, and $\varepsilon / \delta_{m}$}

In MWCO experiments, the observed sieving coefficient, $S_{o}$, was measured for each solute molecular weight (i.e., PEG in this study) in each membrane considered. The hydraulic permeability (i.e., pure water permeance), $\bar{L}_{p}$, of each membrane was measured using dead-end filtration. These experimental $\bar{L}_{p}$ and $S_{o}$ values were used to estimate $\bar{r}, \sigma / \bar{r}$, and $\varepsilon / \delta_{m}$ for each membrane by fitting the experimental $S_{o}$ values to the theoretical $S_{o}$ values calculated using the water and solute transport models.

The data fitting strategy is first described for the case when $J_{v}$ and $k$ are allowed to vary with $r_{c}$. For a particular membrane, the model calculations were started by choosing $\bar{r}$ and $\sigma / \bar{r}$ values that were reasonable (e.g., $\bar{r}=4 \mathrm{~nm}, \sigma / \bar{r}=0.25$ ) and using the pure water permeance, $\bar{L}_{p}$, to estimate $\varepsilon / \delta_{m}$ from Equation (4). This procedure established an initial set of $\bar{r}, \sigma / \bar{r}$, and $\varepsilon / \delta_{m}$ parameters for further calculations. For a given PEG molecular weight, a corresponding solute molecular size, $a$, was calculated using Equation (14), and the diffusion coefficient was calculated using Equation (11). A radially-dependent permeate flux, $J_{v}\left(r_{c}\right)$, was estimated from Equation (17) using experimentally measured $\bar{J}_{v}$ and $\bar{L}_{p}$ values. For a particular membrane pore size, $r$, and a PEG molecular size, $a$, an asymptotic sieving coefficient, $S_{\infty}(r, a)$, was calculated using Equation (12), and $P e_{m}\left(r, a, r_{c}\right)$ was calculated from Equation (10). The calculated $S_{\infty}(r, a)$ and $P e_{m}\left(r, a, r_{c}\right)$ were then inserted into Equation (9) to calculate $S_{a}\left(r, a, r_{c}\right)$. The average actual sieving coefficient for a given membrane with a given PEG molecular weight, $\bar{S}_{a}\left(a, r_{c}\right)$, was calculated by integrating $S_{a}\left(r, a, r_{c}\right)$ over the membrane pore size distribution using Equation (18). Afterwards, $S_{o}$ value was evaluated from $\bar{S}_{a}\left(a, r_{c}\right)$ using the stagnant film model, Equation (21), where $k\left(r_{c}\right)$ was calculated for a given PEG molecular weight using Equation (20).

$S_{o}$ values were calculated for all PEG molecular weights used in the MWCO tests for each membrane by repeating the calculation steps described above. For each membrane, calculated $S_{o}$ values were fit to the experimental $S_{o}$ values. The $\bar{r}$ and $\sigma / \bar{r}$ values were varied, 
and a goodness-of-fit parameter, $\chi^{2}$ [37], between the experimental and calculated $S_{o}$ values was computed. Best fit values of $\bar{r}$ and $\sigma / \bar{r}$ for each membrane were determined by minimizing $\chi^{2}$. A grid-search method for nonlinear least-squares fitting, as explained by Bevington and Robinson [37], was used to identify optimum $\bar{r}$ and $\sigma / \bar{r}$ values having a minimum $\chi^{2}$ value. Wolfram Mathematica 10.0 software was used for all calculations, and the NIntegrate command was used for numerical integration. The range of $\bar{r}$ used in the model fitting was selected based on the nominal pore radii of the membranes. A range of $\sigma / \bar{r}$ was chosen based, in part, on previously reported $\sigma / \bar{r}$ values of UF membranes (e.g., $\sigma / \bar{r}=0.2$ and $0.25[24,28])$. Here, a broader $\sigma / \bar{r}$ range than that of the literature-reported $\sigma / \bar{r}$ values was investigated. In our study, $\bar{r}$ was varied from $1-10 \mathrm{~nm}$, and $\sigma / \bar{r}$ was varied from $0.05-1$. The optimum $\varepsilon / \delta_{m}$ value of each membrane was then calculated from Equation (4) using the best fit $\bar{r}$ and $\sigma / \bar{r}$ values for a particular membrane.

For the case where $J_{v}$ and $k$ do not depend on $r_{c}, J_{v}\left(r_{c}\right)$ in Equation (10) was replaced by $\bar{J}_{v}$, which was the value set during the MWCO experiments. For each PEG molecular weight, the resulting expression for $\mathrm{Pe}_{m}(r, a)$ was used in Equation (9) to calculate $S_{a}(r, a)$ of a particular membrane pore size $r$. The $S_{a}(r, a)$ was then integrated over the pore size distribution, $n(r)$, in Equation (18) to calculate $\bar{S}_{a}(a)$ of a given membrane. Subsequently, $S_{o}$ for each membrane and each PEG molecular weight was calculated from this $\bar{S}_{a}(a)$ value using a stagnant film model, Equation (8), where $\bar{k}$ was calculated using Equation (19). $S_{o}$ values were calculated for all PEG molecular weights considered for each membrane. Afterwards, the strategy for minimizing $\chi^{2}$ explained earlier was used to identify the best fit $\bar{r}$ and $\sigma / \bar{r}$ values for each membrane. 


\section{EXPERIMENTAL}

\subsection{Materials}

Flat-sheet polysulfone ultrafiltration membranes (PS-20, $20 \mathrm{kDa}$ MWCO as specified by the manufacturer) were purchased from Nanostone Water (Eden Prairie, MN) (formerly Ultura and formerly Sepro Membranes, Inc.). Acrylic plates and rubber gaskets of $20 \mathrm{~cm} \times 28 \mathrm{~cm}$ size were obtained from Interstate Plastics (Austin, TX) and Advanced Gasket \& Supply, Inc. (Fort Worth, TX), respectively. Polysulfone (UDEL P-3500 LCD MB) was obtained from Solvay Specialty Polymers (Alpharetta, GA). Dopamine hydrochloride (3-hydroxytyramine hydrochloride), Trizma hydrochloride (Tris-HCl), cyclopentanone, and poly(ethylene glycol) (PEG) were purchased from Sigma Aldrich (St. Louis, MO). Sodium hydroxide (NaOH) and ethanol were purchased from Fisher Scientific (Pittsburgh, PA). 25 mm Puradisc PTFE syringe filters (Whatman) of 0.1, 0.2, 0.45, and $1.0 \mu \mathrm{m}$ pore sizes were purchased from GE Healthcare Life Sciences (Piscataway, NJ). Silicon (Si) wafers (6" diameter) were purchased from Nova Electronic Materials, LLC (Flower Mound, TX). All chemicals were used as received. Ultrapure water (18.2 M $\Omega$-cm at $25^{\circ} \mathrm{C}, 1.2 \mathrm{ppb}$ TOC) was obtained from a Millipore Milli-Q Advantage A10 water purification system (Billerica, MA).

\subsection{Pretreatment and Polydopamine (PDA) Modification of Membranes}

PS-20 UF membranes were pretreated by soaking in ethanol overnight as described previously $[15,16,38]$. The membranes were then rinsed thoroughly with ultrapure water at least four times to displace the ethanol prior to further use. Membranes for PDA modification were cut to the same size as the frame and gasket used for PDA surface modification. The frame and gasket were used to secure the membranes for coating as described elsewhere [15, 16]. An aqueous dopamine solution was prepared by dissolving dopamine hydrochloride in $15 \mathrm{mM}$ Tris buffer solution. The Tris buffer $\mathrm{pH}$ was adjusted to 8.8 before use with $\mathrm{NaOH}$. Each membrane sheet was coated with PDA by exposing its selective face to the aqueous dopamine solution. 
During modification, the membrane sheet was set on a rocking platform shaker (VWR International, Radnor, PA) at a rocking speed of 30 tilts per minute and a tilt level of 4 for the prescribed deposition time. After the desired deposition time was reached, the membrane sheet was rinsed with running ultrapure water and soaked in ethanol for 10 minutes to remove any weakly-bound PDA from the membrane surface. Then the membrane sheet was rinsed thoroughly with several batches of ultrapure water to remove the ethanol and stored in ultrapure water until used. Using a cutting die, the membrane sheet was cut into circular samples having a diameter of $3.83 \mathrm{~cm}$ for use in pure water permeance tests or $6.04 \mathrm{~cm}$ for use in MWCO tests. The PS-20 UF membranes were modified with PDA at various deposition conditions. Initial dopamine concentrations of $0.1,0.5,1,2,4$, and $8 \mathrm{mg} / \mathrm{mL}$ were used at a deposition time of 60 minutes. PDA deposition times were 15, 30, 60, 120, and 240 minutes at an initial dopamine concentration of $2 \mathrm{mg} / \mathrm{mL}$.

\subsection{Ellipsometry}

Polydopamine (PDA) coating thicknesses on dense, nonporous polysulfone (PSf) films were measured using spectroscopic ellipsometry (model M-2000V with CompleteEASE software, J.A. Woollam Co., Inc., Lincoln, NE). 3 wt\% PSf in cyclopentanone solution was prepared and pre-filtered with $1,0.45,0.2$, and $0.1 \mu \mathrm{m}$ syringe filters, in this order, to remove any particulates or contaminants. PSf flat dense films were obtained by spin casting the polymer solution on silicon (Si) wafers at 1,000 rpm for 60 seconds. The method of PSf film preparation is described in detail elsewhere [39]. PDA was coated onto PSf-coated Si wafers using a protocol similar to that used for membrane modification described in section 3.2. Initial dopamine concentrations of $0.1,0.5,1,2,4$, and $8 \mathrm{mg} / \mathrm{mL}$ at a coating time of 60 minutes and deposition times of 15, 30, 60, 120, and 240 minutes at an initial dopamine concentration of $2 \mathrm{mg} / \mathrm{mL}$ were used. After each modification, the coated samples were rinsed thoroughly with ultrapure water 
and air-dried overnight prior to thickness measurement. Samples were rinsed carefully to prevent leaching of PSf from the Si wafers.

Thickness measurements were conducted at variable incidence angles (65, 70, and 75 degrees) and variable wavelengths (370-1,000 nm) on at least 3 different locations for each sample. The PSf layer thickness of each individual sample was measured prior to PDA modification using a Cauchy two-layer model [40]. The first layer was presumed to be silicon dioxide $\left(\mathrm{SiO}_{2}\right)$, whose thickness was measured before spin coating with PSf, and the second layer was the PSf film. For PDA thickness analysis, a third layer was added on top of the PSf and $\mathrm{SiO}_{2}$ layers. The thicknesses of the PSf and $\mathrm{SiO}_{2}$ layers were fixed using values measured on that particular sample prior to PDA modification. The PDA coating thickness was estimated using a General Oscillator (Gen-Osc) layer (provided in the CompleteEASE software) with a TaucLorentz oscillatory model. (The B-Spline layer was initially used, and the Tauc-Lorentz oscillatory model was then used to parameterize the optical constants of the B-Spline layer. After parameterization, the B-Spline layer was replaced by the Gen-Osc layer.) This method of analysis accounts for light absorption of PDA at all wavelengths. More details of the ellipsometry data analysis from light-absorbing thin films can be found elsewhere [40]. We measured a refractive index (n) of 1.73 and a $k$ amplitude of 0.12 at a wavelength $(\lambda)$ of 632.8 $\mathrm{nm}$ for the thickest PDA film, which was coated using an $8 \mathrm{mg} / \mathrm{mL}$ initial dopamine concentration solution and a deposition time of 240 minutes. Analysis of very thin films can introduce uncertainty in the fitted $n$ and k parameters. Thus, for samples with PDA film thicknesses less than $10 \mathrm{~nm}$, an $\mathrm{n}$ value of 1.73 and a k value of 0.12 , obtained from samples with thick PDA coatings, were used instead of allowing the $n$ and $k$ parameters to be fit. Each reported thickness is an average of measurements on at least three locations on each sample, and the uncertainty is reported as one standard deviation. 


\subsection{Pure Water Permeance Measurement}

The pure water flux of unmodified and PDA-modified PS-20 UF membranes was measured by dead-end filtration. The filtration cells, model UHP43, were obtained from Advantec MFS, Inc. (Dublin, CA). The effective filtration area was $11.5 \mathrm{~cm}^{2}$. The applied transmembrane pressure $\left(T M P_{n}\right)$ was 30 psi (2.1 bar). During filtration experiments, the permeate mass was recorded as a function of time. At steady state (i.e., when the pure water flux was constant), the slope of permeate mass $(m)$ versus filtration time $(t)$, the density of water $\left(\rho_{\text {water }}\right)$, and the effective filtration area $(A)$ were used to determine pure water permeate flux as follows [15, 41, 42]:

$$
\bar{J}_{p w}=\frac{1}{\rho_{\text {water }} A}\left(\frac{\Delta m}{\Delta t}\right)
$$

The membrane hydraulic permeability or pure water permeance, $\bar{L}_{p}$, was calculated from pure water flux divided by $T M P_{n}$ as shown in Equation (2). The reported pure water permeance values are averages from measurements of at least three samples. One standard deviation is reported as the uncertainty and presented as an error bar in figures containing these data.

\subsection{Molecular Weight Cutoff}

Molecular weight cutoff (MWCO) measurements were conducted in continuous dead-end filtration of aqueous poly(ethylene glycol) (PEG) solutions. PEG samples with 4, 8, 10, 12, 20, 35,100 , and $200 \mathrm{kDa}$ molecular weights were used. Aqueous solutions containing $0.1 \mathrm{wt} \%$ (1,000 ppm) PEG were prepared with one PEG molecular weight for each solution. The filtration was conducted with PEG solutions of one molecular weight at a time in order of ascending (i.e., low to high) molecular weight. The filtration system was cleaned thoroughly with ultrapure water between filtrations of PEG solutions of different molecular weights. 
Except for the choice of solute, the filtration setup was constructed and operated according to ASTM standard E1343 - 90 [43]. The ASTM standard uses dextran as a solute marker [43]. Other literature studies also report the use of PEG to determine MWCO [44-47].

Dead-end filtration cells (model 8200, Millipore, Corp., Billerica, MA), with an effective filtration area of $28.7 \mathrm{~cm}^{2}$, were used. The PEG solution in the dead-end filtration cells was stirred at $250 \mathrm{rpm}$ ( $\omega \approx 26.2$ radians/s) at all times during the experiments. The feed flow rate was $100 \pm 10 \mathrm{~mL} / \mathrm{min}$, and feed pressure was $6 \pm 0.5 \mathrm{psig}$. The permeate flow rate was $0.17 \pm 0.01$ $\mathrm{mL} / \mathrm{min}$ and was controlled by a peristaltic pump (catalog number for drive: 7522-30, for head: 7519-20, for cartridge: 7519-85, Cole-Parmer, Vernon Hills, IL) with feedback control from a permeate flow meter (model number: M12P-ABD-11-0-S, Bronkhorst, Bethlehem, PA). This permeate flow rate corresponds to an average permeate flux, $\bar{J}_{V}$, of $0.0001 \mathrm{~cm} / \mathrm{s}$ or $3.6 \mathrm{~L} / \mathrm{m}^{2} / \mathrm{h}$ (LMH). A very low permeate flow rate was used to minimize concentration polarization. Each filtration test with each PEG molecular weight was run for at least 30 minutes prior to collecting feed and permeate samples to ensure that the system had reached steady state. The feed and permeate sample concentrations were analyzed using a total organic carbon analyzer (TOCVcsh, Shimadzu Corp., Japan). The observed sieving coefficients, $S_{o}$, were calculated using Equation (7). The MWCO values were determined from the actual PEG rejections, calculated from the $S_{o}$ data, as discussed in more detail in the Results and Discussion section (section 4.3).

\section{RESUltS AND DisCUSSION}

\subsection{Polydopamine (PDA) Surface Coating Thickness}

PDA was coated on nonporous PSf dense films. PSf film thicknesses were in the range of $160-170 \mathrm{~nm}$. The PDA coating thicknesses determined by spectroscopic ellipsometry are presented in Figure 2. The PDA surface coating thickness increased with increasing initial dopamine concentration and increasing deposition time. These trends correspond qualitatively to similar data reported by others $[14,18,19,48-54]$. The surface coating thickness was less than 
$10 \mathrm{~nm}$ at $0.1 \mathrm{mg} / \mathrm{mL}$ initial dopamine concentration for all deposition times studied. At the most aggressive modification condition (i.e., at $8 \mathrm{mg} / \mathrm{mL}$ initial dopamine concentration and 240 minutes coating time), the PDA surface coating thickness was nearly $50 \mathrm{~nm}$.

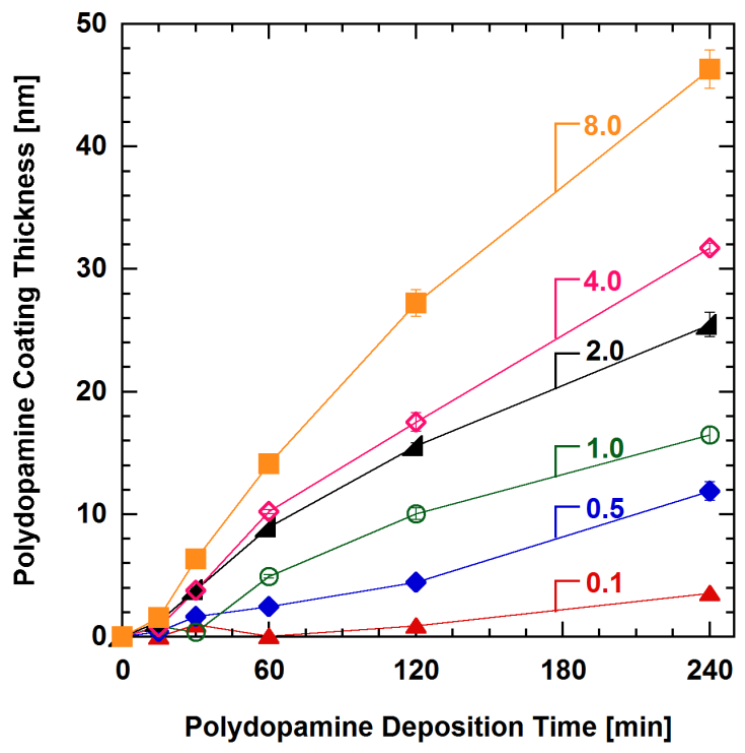

Figure 2. PDA coating thickness on dense PSf films (measured by ellipsometry) as a function of PDA deposition time and initial dopamine concentration. Numbers noted in the plot represent initial dopamine coating solution concentration in mg/mL.

The thickness of PDA coatings has been evaluated on many substrates, both inorganic and organic [14, 18, 19, 48-54]. Regardless of the substrate material, PDA coating thickness reportedly increases as initial dopamine coating solution concentration increases [49, 50, 52, 53] or deposition time increases [14, 18, 19, 48, 50-54]. Table 1 summarizes literature reports of PDA coating thickness on various substrates. All data shown are at an initial dopamine concentration of $2 \mathrm{mg} / \mathrm{mL}$ and a deposition time of 4 hours. Unless otherwise noted, these studies were performed at ambient conditions. The reported thicknesses varied from 2 to $45 \mathrm{~nm}$ even though the initial dopamine coating solution concentration and deposition time were the same. There was no obvious correlation of coating thickness with either buffer concentration or buffer solution $\mathrm{pH}$. The reported thickness values were different even for studies using the same 
substrate, Tris buffer concentration, and thickness measurement technique (i.e., Ball et al., 2012 [49] and Bernsmann et al., 2009 [55]). Most of these studies did not report detailed stirring conditions of the coating solution during PDA deposition. However, because oxygen is required to convert dopamine to PDA [56-60], variations in dissolved oxygen content in the PDA coating solution due to different stirring conditions could influence deposition thickness. Although this hypothesis concerning the variability in literature reports cannot be definitively tested using the data in Table 1, it is one potential avenue for future studies.

Table 1. Summary of reported PDA deposition thicknesses on various substrates using 2 $\mathrm{mg} / \mathrm{mL}$ initial dopamine coating solution concentration and 4 hours of deposition time.

\begin{tabular}{|c|c|c|c|c|c|}
\hline Reference & Substrate & $\begin{array}{c}\text { Tris buffer } \\
\text { concentration } \\
\text { (mM) }\end{array}$ & $\begin{array}{c}\text { Tris } \\
\text { buffer } \\
\mathbf{p H}\end{array}$ & $\begin{array}{c}\text { Thickness } \\
\text { measurement } \\
\text { technique }\end{array}$ & $\begin{array}{c}\text { PDA } \\
\text { deposition } \\
\text { thickness } \\
\text { (nm) }\end{array}$ \\
\hline This study & $\begin{array}{c}\text { PSf-coated } \\
\text { Si }\end{array}$ & 15 & 8.8 & Ellipsometry & 25 \\
\hline Ball et al., 2012 [49] & $\mathrm{Si}$ & 50 & 8.5 & Ellipsometry & 8 \\
\hline $\begin{array}{c}\text { Jiang et al., 2011 } \\
\text { [50] }\end{array}$ & $\mathrm{Si}$ & 10 & 8.5 & Ellipsometry & $7^{*}$ \\
\hline $\begin{array}{c}\text { Jiang et al., 2011 } \\
\text { [50] }\end{array}$ & $\begin{array}{c}\text { PVDF- } \\
\text { coated Si }\end{array}$ & 10 & 8.5 & Ellipsometry & $22^{*}$ \\
\hline $\begin{array}{c}\text { McCloskey et al., } \\
\text { 2010 [18] }\end{array}$ & $\begin{array}{c}\text { PSf-coated } \\
\text { Si }\end{array}$ & 15 & 8.8 & Ellipsometry & 45 \\
\hline Pan et al., 2009 [53] & Si & 100 & 9.4 & Stylus profiler & 38 \\
\hline $\begin{array}{c}\text { Bernsmann et al., } \\
\text { 2009 [55] }\end{array}$ & $\mathrm{Si}$ & 50 & 8.5 & Ellipsometry & 2 \\
\hline Li et al., 2009 [54] & $\mathrm{Si}$ & N/A & 8.5 & Stylus profiler & 26 \\
\hline $\begin{array}{c}\text { Lee et al., 2007 [14] } \\
\text { Si }\end{array}$ & 10 & 8.5 & $\begin{array}{c}\text { Atomic Force } \\
\text { Microscopy }\end{array}$ & 25 \\
\hline
\end{tabular}

Note: All PDA deposition thickness values were extracted from plots reported in the literature using UN-SCAN-IT 6.0 software. ${ }^{*}$ PDA modification at $30^{\circ} \mathrm{C}$.

\subsection{Pure Water Permeance}

The influence of initial dopamine coating solution concentration and deposition time on pure water permeance of PS-20 UF membranes is presented in Figure 3(a) and Figure 3(b), 
respectively. PDA coating thicknesses, determined using ellipsometry on dense PSf films coated with PDA under identical conditions, are also included in Figure 3. The pure water permeance of PDA-modified membranes decreased with increasing initial dopamine coating solution concentration and with increasing deposition time. This decrease in pure water permeance was presumably due to the growth of increasingly thick PDA coatings and, also, pore narrowing and pore blockage $[18,19]$. However, the pure water permeance values of membranes modified with PDA at low initial dopamine concentrations (i.e., 0.1 and $0.5 \mathrm{mg} / \mathrm{mL}$ ) or short coating time (i.e., 15 minutes) remained near those of unmodified membranes, possibly because of relatively thin PDA coatings at these coating conditions. A significant pure water permeance decrease was observed at moderate initial dopamine concentrations or moderate deposition times, but the decrease was more gradual at high initial dopamine concentrations or long deposition times. The PDA coating thickness changed more gradually at more extensive PDA coating conditions and reached a plateau at long coating times [18]. Perhaps the gradual change in PDA coating thickness led to slower pure water permeance reduction at extensive PDA modification conditions. Similar trends in pure water flux or hydraulic permeability of unmodified and PDAmodified UF and RO membranes were observed by Miller et al. [15], McCloskey et al. [18], and Cheng et al. [19]. 

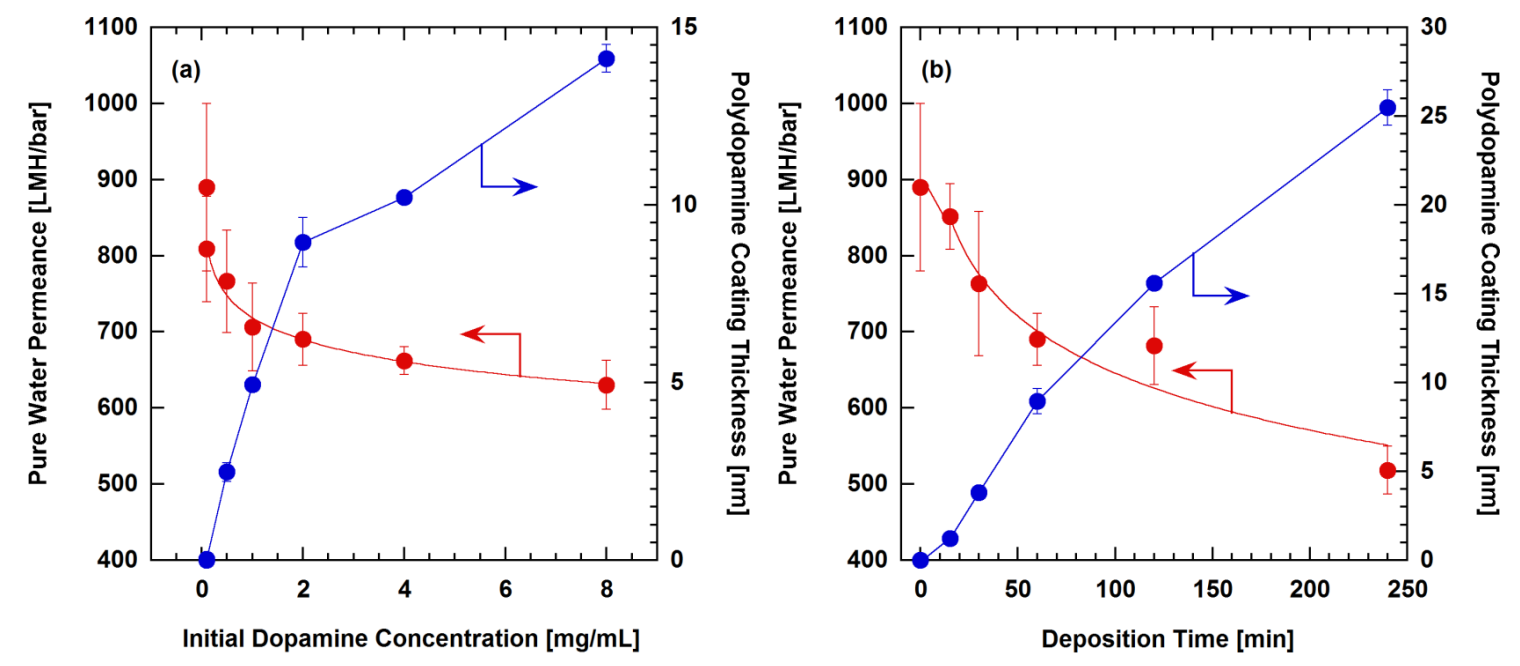

Figure 3. Influence of: (a) initial dopamine coating solution concentration and (b) PDA deposition time on pure water permeance of PDA-modified UF membranes (PS-20) and PDA coating thickness on dense PSf film measured by ellipsometry. A deposition time of 60 minutes was used in (a) and an initial dopamine concentration of $2 \mathrm{mg} / \mathrm{mL}$ was used in (b). The lines are to guide the eye.

\subsection{Molecular Weight Cutoff and Nominal Pore Size}

In this study, the molecular weight cutoff (MWCO) was defined to be the molecular weight of PEG for which the actual membrane rejection, $R_{a}$, was $90 \%$ in the ASTM MWCO test $[2,29,43,61,62]$. The ASTM standard does not account for concentration polarization during the filtration tests, so the observed rejection is used directly to determine the MWCO. However, when concentration polarization is significant, the observed rejection, $R_{o}$, is lower than the actual rejection, $R_{a}$, and the MWCO value determined from the $R_{o}$ curve can be significantly higher than the MWCO determined from the $R_{a}$ curve [31]. Causserand et al. estimated the $R_{a}$ values from $R_{o}$ values, using a stagnant film model (with average $k$ and $J_{v}$ ), and compared the retention profiles and MWCO values from these two cases [31]. In their study, the MWCO was overestimated when the observed rejection was used directly, and thus, the actual rejection instead should be used to determine the true MWCO, since the actual rejection represents the true selective properties of the membranes [31]. Our MWCO analysis followed the approach 
proposed by Causserand et al., so the $R_{a}$ values of PEG were calculated and used to determine the MWCO in our study.

Unless a filtration is conducted at very low boundary layer Peclet numbers, where $R_{a}$ is equal to $R_{o}$, the actual rejection may not be reflected in the observed MWCO values. Several studies proposed Peclet number ranges in the membrane boundary layer (i.e., $P e_{B L}=\bar{J}_{V} / \bar{k}$ ) where concentration polarization could be neglected (and, therefore, $R_{a} \approx R_{o}$ ). These proposed ranges are: (i) $0.405<\bar{J}_{V} / \bar{k}<0.693$, (ii) $\bar{J}_{V} / \bar{k}<1$, and (iii) $\bar{J}_{V} / \bar{k}<0.18$ [63]. In general, $\bar{J}_{V} / \bar{k}$ increases with increasing PEG molecular weight due to decreased PEG diffusivity (which decreases $\bar{k}$ ) of larger PEG molecules [31]. In this study, although $\bar{J}_{V} / \bar{k}$ was small (less than 1) for most PEGs ( $4-35 \mathrm{kDa})$, but $\bar{J}_{V} / \bar{k}$ was greater than 1 for 100 and $200 \mathrm{kDa}$ PEGs. Thus, concentration polarization could not be neglected, at least for the highest molecular weight PEGs considered.

A stagnant film model, Equation (8), with $\bar{k}$ calculated using Equation (19) was used to estimate $S_{a}$ values of PEG from the experimental $S_{o}$ values acquired from the MWCO filtration tests. Percent actual PEG rejection (\% $\left.R_{a}=R_{a} \times 100\right)$ was calculated from $S_{a}$ using Equation (6). The concentration polarization model (i.e., stagnant film model) was mainly used with $\bar{k}$ and $\bar{J}_{v}$ in this MWCO determination, following Causserand et al.'s study [31]. This model was also used with radially-dependent $k$ and $J_{v}\left(k\left(r_{c}\right)\right.$ and $\left.J_{v}\left(r_{c}\right)\right)$ in the mean pore size and pore size distribution analysis, and the results were compared with those obtained using $\bar{k}$ and $\bar{J}_{v}$ as discussed later.

Figure 4 and Figure 5 present percent actual PEG rejection values, $\% R_{a}$, as a function of PEG molecular weight for PS-20 UF membranes modified with PDA at various initial dopamine coating solution concentrations and deposition times, respectively. MWCO values were determined from the PEG molecular weights that gave 90\% $R_{a}$ values in Figure 4 and Figure 5. These values, estimated by interpolating between the two PEG molecular weights closest to an 
$R_{a}$ value of $90 \%$, are recorded in Table 2 and Table 3. Moreover, the steepness of the PEG rejection curves qualitatively reflects the width of the membrane pore size distribution [25, 6466]. A steeper slope suggests a narrower pore size distribution [25, 64-66]. For membranes modified at higher initial dopamine coating solution concentrations or longer times, the slopes of the rejection curves appear, qualitatively, to be steeper (cf., Figure 4 and Figure 5) than those of membranes modified at lower initial dopamine coating solution concentrations or shorter times. Thus, more extensive PDA deposition appears to narrow the pore size distribution.
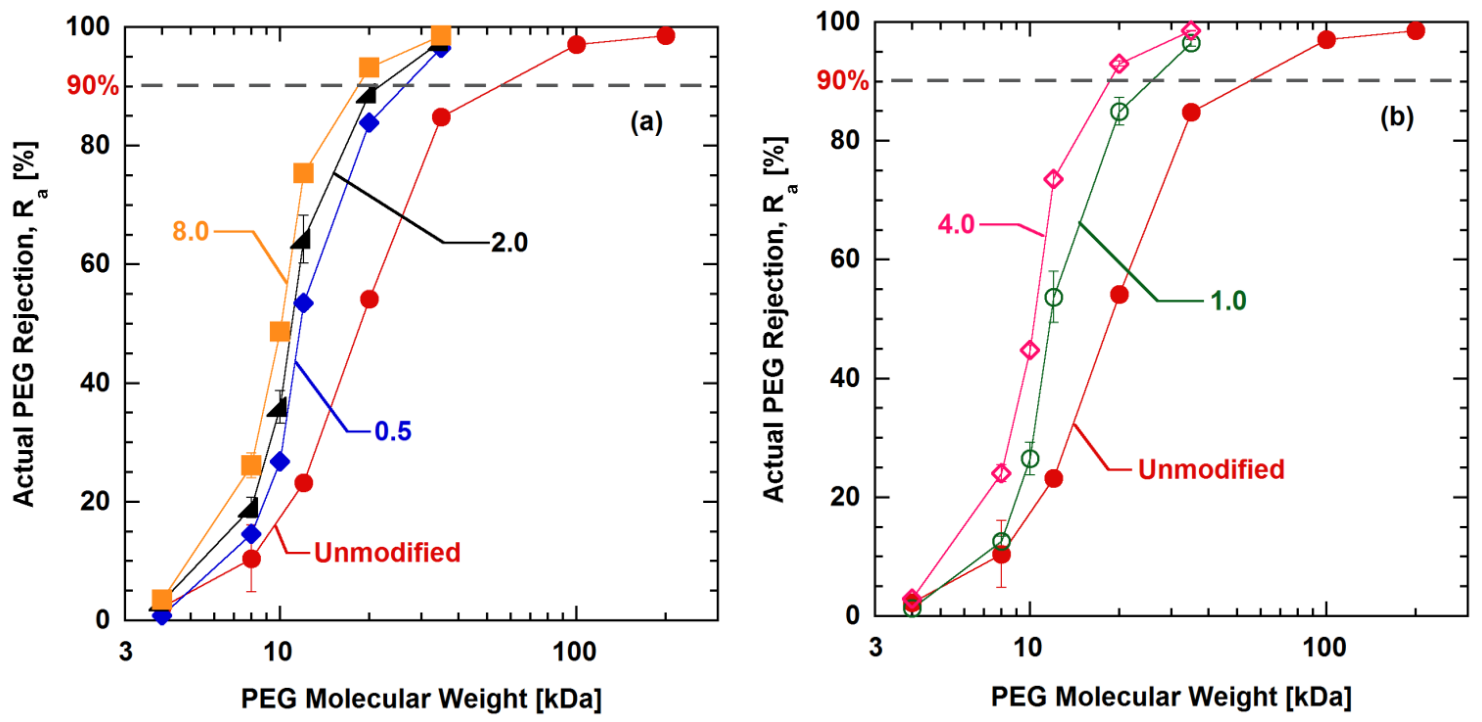

Figure 4. Actual rejection values of poly(ethylene glycol) (PEG) as a function of PEG molecular weight for PS-20 UF membranes modified with PDA at various initial dopamine coating solution concentrations. The numbers in (a) and (b) represent initial dopamine concentration in $\mathrm{mg} / \mathrm{mL}$. A deposition time of 60 minutes was used. Data are plotted separately in (a) and (b) to permit easier viewing of the rejection curves. The solid and dashed lines are provided to guide the eye. 

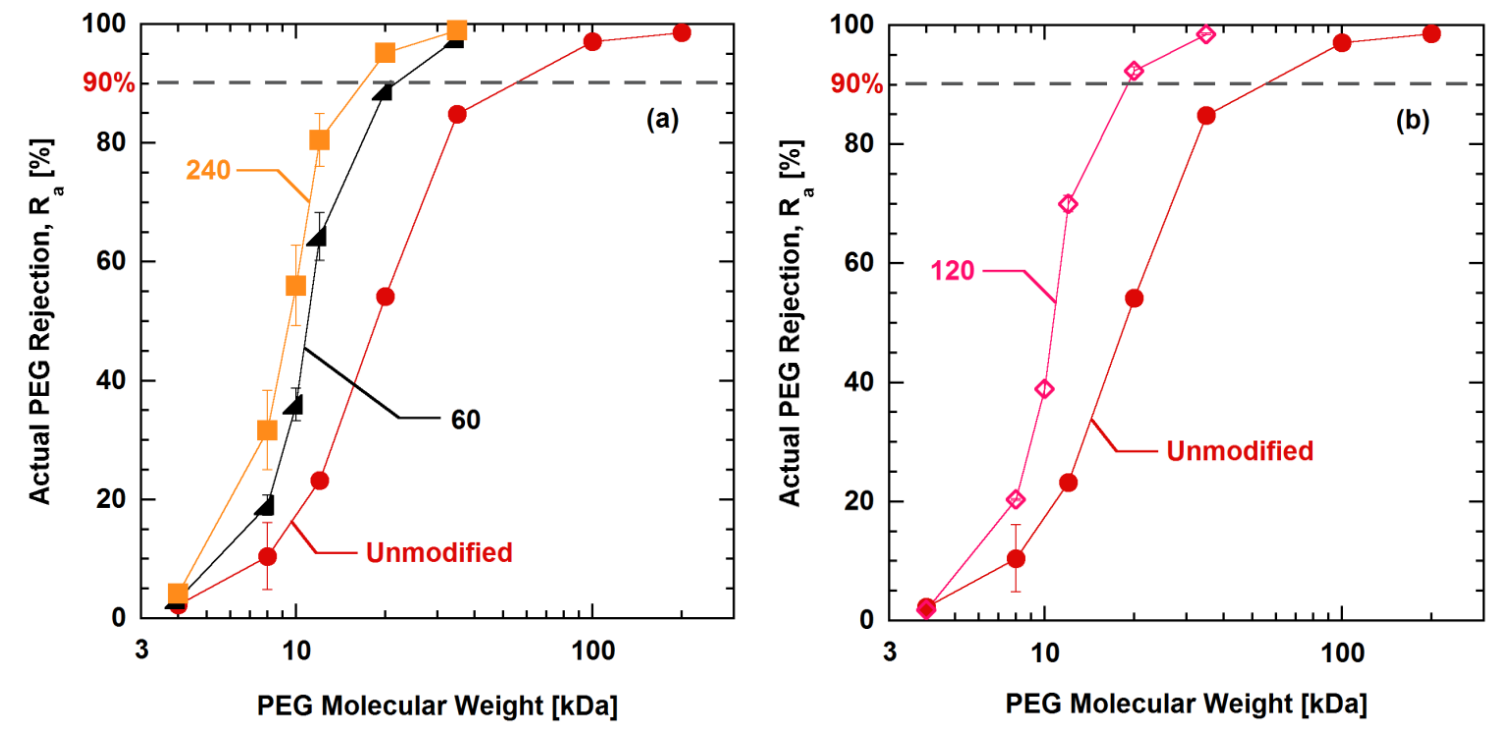

Figure 5. Actual rejection values of poly(ethylene glycol) (PEG) as a function of PEG molecular weight for PS-20 UF membranes modified with PDA at various PDA deposition times. The numbers in (a) and (b) represent PDA deposition time in minutes. An initial dopamine concentration of $2 \mathrm{mg} / \mathrm{mL}$ was used. Data are plotted separately in (a) and (b) to permit easier viewing of the rejection curves. The solid and dashed lines are provided to guide the eye.

The nominal (or effective) pore sizes of unmodified and PDA-modified membranes are also presented in Table 2 and Table 3. These values were PEG Stokes radii estimated from the MWCO data using Equation (14). One measure of the nominal pore radius of UF membranes is the Stokes radius of a solute molecule with a molecular weight equal to the MWCO value [16]. Others proposed estimation of the nominal membrane pore size from the molecular size of the solute marker [67] or more specifically, its radius of gyration $\left(R_{g}\right)$ [3]. The radius of gyration of PEG is close to its Stokes radius $\left(R_{s}\right)\left(R_{s} \approx 0.875 R_{g}\right)$ [68]. In this study, the PEG Stokes radius was used as an approximation of the membrane nominal pore size. Other similar correlations between PEG Stokes radius and molecular weight are reported in the literature, but the values of front factors and exponents on $M$ are somewhat different from those in Equation (14) [34, 45, 68]. Using other PEG Stokes radius correlations gives somewhat different values of the nominal 
pore size, but the relative changes in nominal pore radius of unmodified and PDA-modified membranes remained similar to those reported here.

Table 2. Influence of initial dopamine concentration on MWCO, nominal pore radius, PDA coating thickness estimated from changes in MWCO, and PDA coating thickness from ellipsometry on flat dense PSf films.

\begin{tabular}{|c|c|c|c|c|}
\hline $\begin{array}{c}\text { Initial dopamine } \\
\text { concentration } \\
\text { (mg/mL) }\end{array}$ & $\begin{array}{c}\text { MWCO } \\
\mathbf{( k D a )}\end{array}$ & $\begin{array}{c}\text { Nominal pore } \\
\text { radius from } \\
\text { MWCO (nm) }\end{array}$ & $\begin{array}{c}\text { PDA coating } \\
\text { thickness from } \\
\text { changes in } \\
\text { MWCO (nm) }\end{array}$ & $\begin{array}{c}\text { PDA coating } \\
\text { thickness from } \\
\text { ellipsometry on } \\
\text { dense films (nm) }\end{array}$ \\
\hline Unmodified & $54 \pm 2$ & $7.3 \pm 0.2$ & & \\
\hline 0.5 & $26.2 \pm 0.4$ & $4.84 \pm 0.04$ & 2.4 & $2.5 \pm 0.3$ \\
\hline 1 & $25 \pm 2$ & $4.7 \pm 0.2$ & 2.5 & $4.9 \pm 0.2$ \\
\hline 2 & $21 \pm 2$ & $4.3 \pm 0.2$ & 2.9 & $9.0 \pm 0.7$ \\
\hline 4 & $18.5 \pm 0.3$ & $3.98 \pm 0.03$ & 3.3 & $10.2 \pm 0.2$ \\
\hline 8 & $18.2 \pm 0.2$ & $3.95 \pm 0.03$ & 3.3 & $14.1 \pm 0.4$ \\
\hline
\end{tabular}

Note: All samples (except unmodified membranes) were modified using a PDA deposition time of 60 minutes. Each reported MWCO is an average of MWCO values of three membrane samples, and the uncertainties represent one standard deviation. The uncertainties of nominal pore radius are one standard deviation and were determined from propagation of errors [37].

Table 3. Influence of PDA deposition time on MWCO, nominal pore radius, PDA coating thickness estimated from changes in MWCO, and PDA coating thickness from ellipsometry on flat dense PSf films.

\begin{tabular}{|c|c|c|c|c|}
\hline $\begin{array}{c}\text { Deposition time } \\
\text { (minutes) }\end{array}$ & $\begin{array}{c}\text { MWCO } \\
\text { (kDa) }\end{array}$ & $\begin{array}{c}\text { Nominal pore } \\
\text { radius from } \\
\text { MWCO (nm) }\end{array}$ & $\begin{array}{c}\text { PDA coating } \\
\text { thickness from } \\
\text { changes in } \\
\text { MWCO (nm) }\end{array}$ & $\begin{array}{c}\text { PDA coating } \\
\text { thickness from } \\
\text { ellipsometry on } \\
\text { dense films (nm) }\end{array}$ \\
\hline Unmodified & $54 \pm 2$ & $7.3 \pm 0.2$ & & \\
\hline 60 & $21 \pm 2$ & $4.3 \pm 0.2$ & 2.9 & $9.0 \pm 0.7$ \\
\hline 120 & $19.0 \pm 0.3$ & $4.04 \pm 0.04$ & 3.2 & $15.6 \pm 0.2$ \\
\hline 240 & $17 \pm 2$ & $3.7 \pm 0.2$ & 3.5 & $25 \pm 1$ \\
\hline
\end{tabular}

Note: All samples (except unmodified membranes) were modified using an initial dopamine coating solution concentration of $2 \mathrm{mg} / \mathrm{mL}$. Each reported MWCO is an average of MWCO values of three membrane samples, and the uncertainties represent one standard deviation. The uncertainties of nominal pore radius are one standard deviation and were determined from propagation of errors [37]. 
The MWCO of unmodified PS-20 UF membranes determined in our experiments was 54 $\mathrm{kDa}$, which was higher than that specified by the manufacturer (i.e., $20 \mathrm{kDa}$ ). The manufacturer determines the MWCO using constant TMP crossflow filtration of $0.1 \mathrm{wt} \%$ aqueous PEG solution at $1.2 \mathrm{gal} / \mathrm{min}$ feed flow rate and $30 \mathrm{psig}$ feed pressure [69]. Because their operating conditions, including feed pressure, permeate flow rate, and crossflow filtration mode, were different from those specified by the ASTM standard used in this study, the manufacturerreported MWCO value may be different from that determined in this study [70, 71]. Variations in TMP and permeate flow rate can lead to differences in observed rejection values and, therefore, different MWCO values [28, 31, 72, 73]. Several studies reported a deviation in experimentally determined MWCO values from manufacturers' specifications due to variations in MWCO test conditions [28, 63, 67]. In addition, the membrane manufacturer does not apply a concentration polarization correction to their PEG rejection data, so observed PEG rejections are used to specify the MWCO [69]. In our study, as explained above, a stagnant film model was used to calculate actual PEG rejections for the MWCO determination. Variations in MWCO values due to concentration polarization corrections have been reported [31].

Based on the results in Table 2 and Table 3, the MWCO and nominal pore radius of PS20 UF membranes decrease with increasing initial dopamine coating solution concentration or deposition time. Thus, PDA likely deposits not only on the surface of the membrane but also in its pores, thereby changing membrane pore size and possibly pore size distribution. Therefore, increasing the initial dopamine coating solution concentration or coating time leads to thicker PDA coatings on the membrane surface and to reductions in nominal pore size due to pore narrowing.

PDA coating thicknesses measured by ellipsometry are also presented in Table 2 and Table 3. The coating thickness estimated from changes in MWCO was calculated by subtracting the nominal pore radius of a PDA-modified membrane from that of an unmodified membrane. A 
schematic of PDA coating on a PSf surface (estimated via ellipsometry) and the reduction of nominal pore size (estimated from MWCO measurements) is presented in Figure 6. Based on the rapid diffusion of dopamine and oxygen in water over distances corresponding to the thickness of membranes used in this study, the PDA is believed to have coated the entirety of the porous membrane structure [74-77]. PDA thickness values determined from ellipsometry and estimated from MWCO values are plotted for comparison in Figure 7.
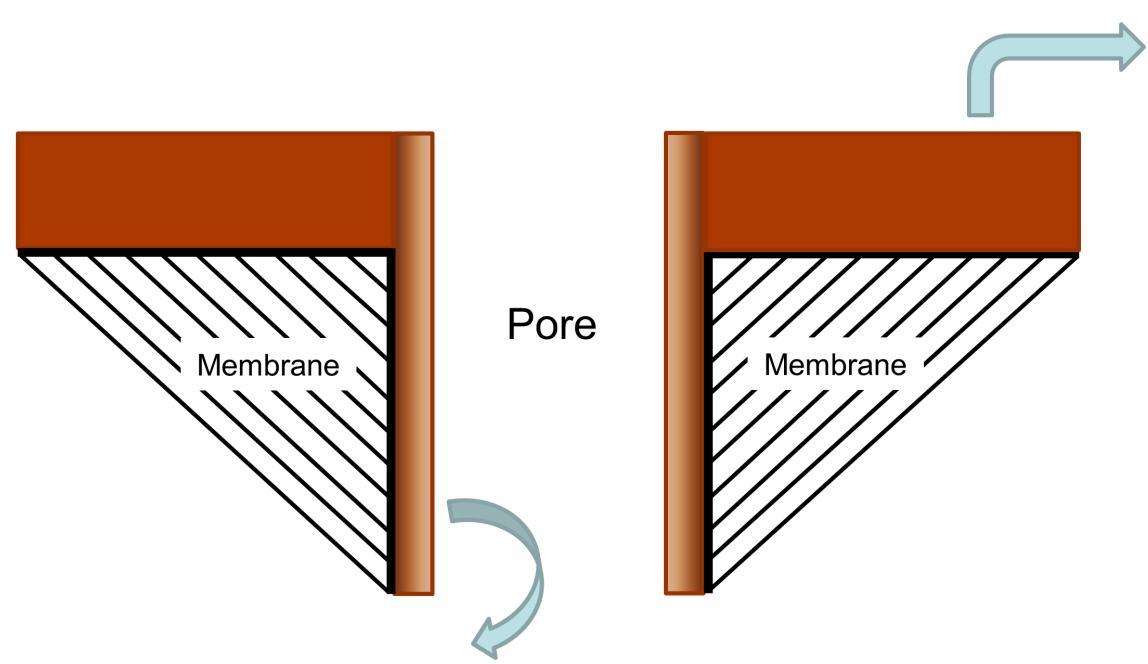

Coating thickness from ellipsometry on dense films

\section{Coating thickness from changes in MWCO of membrane}

Figure 6. A diagram showing PDA coating thickness from ellipsometry on dense film and PDA coating thickness estimated from changes in molecular weight cutoff. 

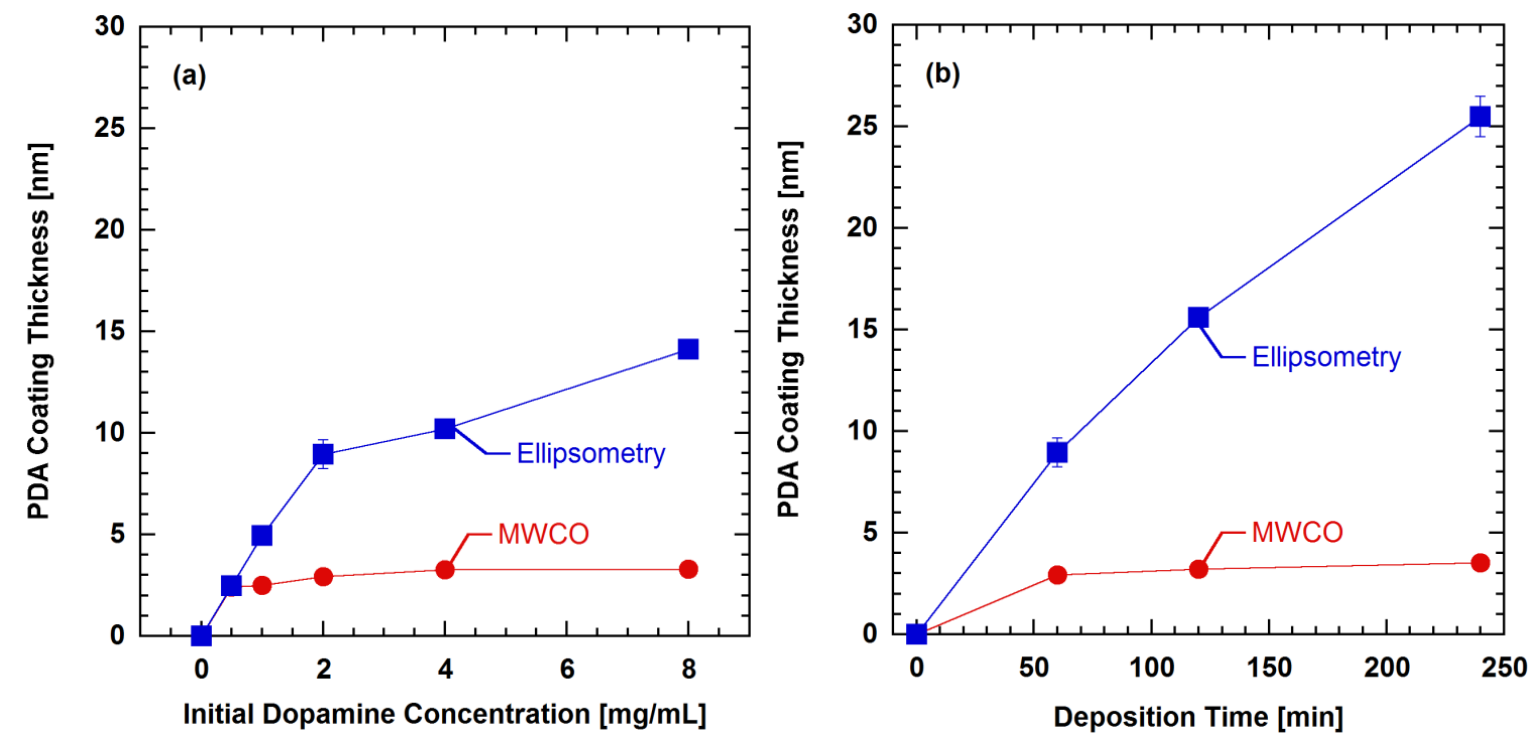

Figure 7. Comparison of PDA thickness from ellipsometry measurements on PSf films ( $\square$ ) and PDA thickness estimated from nominal pore size changes from MWCO data $(\bullet)$. A deposition time of 60 minutes was used in (a) and an initial dopamine concentration of $2 \mathrm{mg} / \mathrm{mL}$ was used in (b).

Based on Figure 7(a) and Figure 7(b), the PDA coating thickness on the surface (as characterized by ellipsometry) increased monotonically with increasing initial dopamine concentration or coating time. However, the PDA coating thickness inside the membrane pores (as characterized by pore size changes from MWCO) initially increased at low initial dopamine concentration or deposition time and then reached a plateau. A possible explanation for this phenomenon is that the membrane pore size cannot decrease without limit (i.e., if PDA fills a pore, there can be no further deposition), whereas PDA deposition on the membrane surface is not subject to such a limitation. However, further study is needed to completely understand this phenomenon.

\subsection{Selectivity and Permeability Tradeoff}

To gauge the impact of PDA deposition on the separation properties of membranes coated under various conditions, PEG rejection was measured as a function of PDA coating conditions. In our study, PEG of very low molecular weight (i.e., 4 kDa PEG) was poorly 
rejected by the membranes at all coating conditions. PEG samples of high molecular weight were almost completely rejected by PDA-modified membranes (e.g., 35 kDa PEG), and even by uncoated membranes (e.g., 100 and 200 kDa PEGs). Thus, at the extremes of the PEG molecular weight range studied, there was relatively little change in rejection with coating conditions. From Figure 4 and Figure 5, large changes in rejection as a function of coating conditions were observed for intermediate PEG samples (i.e., 12 and $20 \mathrm{kDa}$ PEG). The separation factor, $\alpha$, which represents the retention capability of the membranes, was calculated for the 12 and $20 \mathrm{kDa}$ PEG samples according to [24]:

$$
\alpha=\frac{1}{S_{a}}=\frac{1}{\left(1-R_{a}\right)}
$$

Separation factors of unmodified and PDA-modified membranes are presented as a function of membrane hydraulic permeability (i.e., pure water permeance) in Figure 8. These plots show a correlation between membrane hydraulic permeability and separation factor. Membranes with a higher hydraulic permeability had a lower separation factor, and vice versa. Regardless of the modification conditions, PDA-modified membranes with similar hydraulic permeabilities had similar separation factors. Additionally, among the 12 and $20 \mathrm{kDa}$ PEG molecules, the larger PEG probe molecule showed a greater change in rejection properties with changes in hydraulic permeability brought about by PDA deposition. The separation properties of large solutes should be more sensitive to changes in pore size than those of small solutes as long as the large solutes are not completely excluded from the pores. Generally, the ratio of solute size to membrane pore size governs membrane separation properties [8, 30]. 

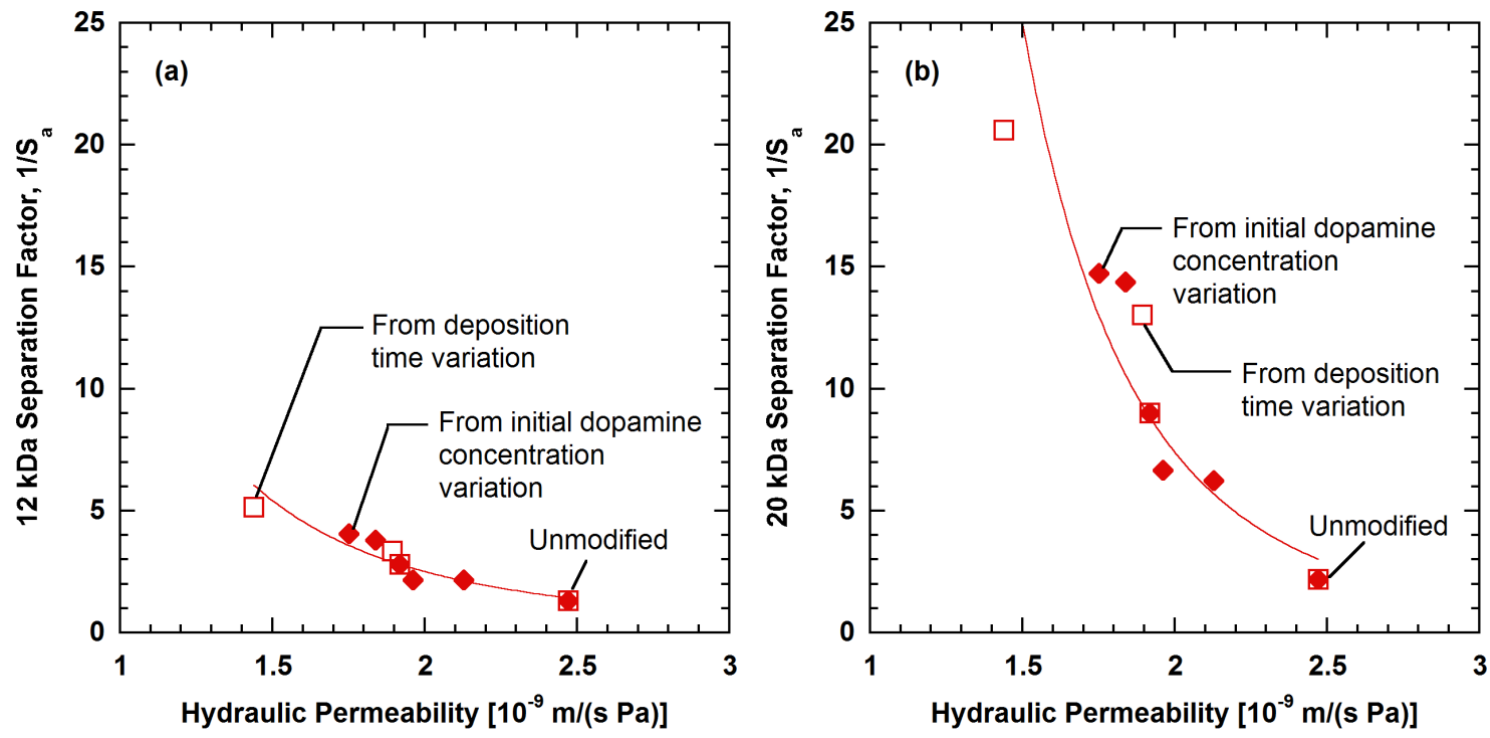

Figure 8. Effect of PDA deposition conditions on separation factor and hydraulic permeability of PS-20 UF membranes modified with PDA at various initial dopamine concentrations ( $\bullet$ ) and deposition times $(\square)$. The solutes used to calculate the separation factor were (a) $12 \mathrm{kDa}$ PEG and (b) $20 \mathrm{kDa}$ PEG. The lines are drawn to guide the eye.

In a related correlation, Figure 9 presents pure water permeance and hydraulic permeability as a function of MWCO for unmodified and PDA-modified PS-20 membranes.

Figure 9 provides another illustration of the tradeoff between water permeation and rejection properties. Generally, a reduction in membrane pore size leads to higher solute retention (i.e., higher separation factor or lower MWCO) but reduced water transport. A similar effect of membrane permeability on separation properties of a variety of UF membranes was reported by Mehta and Zydney [24]. This tradeoff is at least qualitatively reminiscent of those observed for RO membranes [78] and gas separation membranes [79, 80]. 


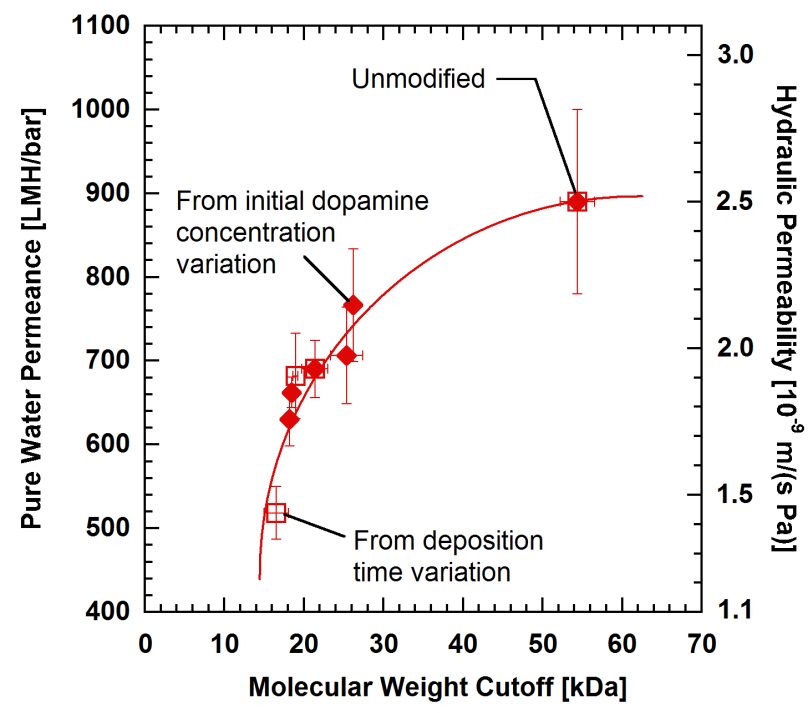

Figure 9. Effect of change in molecular weight cutoff of PS-20 UF membranes modified with PDA at various initial dopamine concentrations ( $\diamond$ ) and deposition times ( $\square$ ) on pure water permeance (hydraulic permeability). The lines are to guide the eye.

\subsection{Mean Pore Size and Pore Size Distribution Analysis}

The effect of PDA deposition conditions on mean pore size and pore size distribution of PDA-modified PS-20 UF membranes was further explored via modeling as described in the Theoretical Background section. The $S_{o}$ values calculated using the radially-dependent mass transfer coefficient, $k\left(r_{c}\right)$, and permeate flux, $J_{v}\left(r_{c}\right)$, were compared with those estimated using average parameters $\bar{k}$ and $\bar{J}_{V}$. The best fit $\bar{r}$ and $\sigma$ parameters from calculations using $k\left(r_{c}\right)$ and $J_{v}\left(r_{c}\right)$ are presented later in this section, and results based on $\bar{k}$ and $\bar{J}_{V}$ are presented in the supplementary information (cf., Figure S.1). These two approaches provided very similar absolute values and trends for $\bar{r}$ and $\sigma$. In addition, these different approaches provided nearly identical fits of calculated $S_{o}$ values to experimental $S_{o}$ values at PEG molecular weights of 4 $35 \mathrm{kDa}$. However, the use of $k\left(r_{c}\right)$ led to improved $S_{o}$ data fitting at higher PEG molecular weights (i.e., 100 and $200 \mathrm{kDa}$ ) compared to fits using $\bar{k}$. This result was perhaps due to a better prediction of concentration polarization when using $k\left(r_{c}\right)$ compared to using $\bar{k}$ for molecules with a high potential for concentration polarization, such as high molecular weight 
PEGs. Other modelling results presented in this section are based on the model calculations using $k\left(r_{c}\right)$ and $J_{v}\left(r_{c}\right)$.

Figure 10 presents calculated and experimental $S_{o}$ values of membranes modified with PDA at various initial dopamine concentrations, and Figure 11 presents similar data for membranes modified with PDA at different deposition times. The solid curves in Figure 10 and Figure 11 represent $S_{o}$ profiles from the model. The model fits in Figure 10 and Figure 11 are considered to be in good agreement with the experimental data. The experimental and calculated $S_{o}$ values of unmodified and PDA-modified membranes are also recorded in Table S.1 and Table S.2 in the supplementary information.
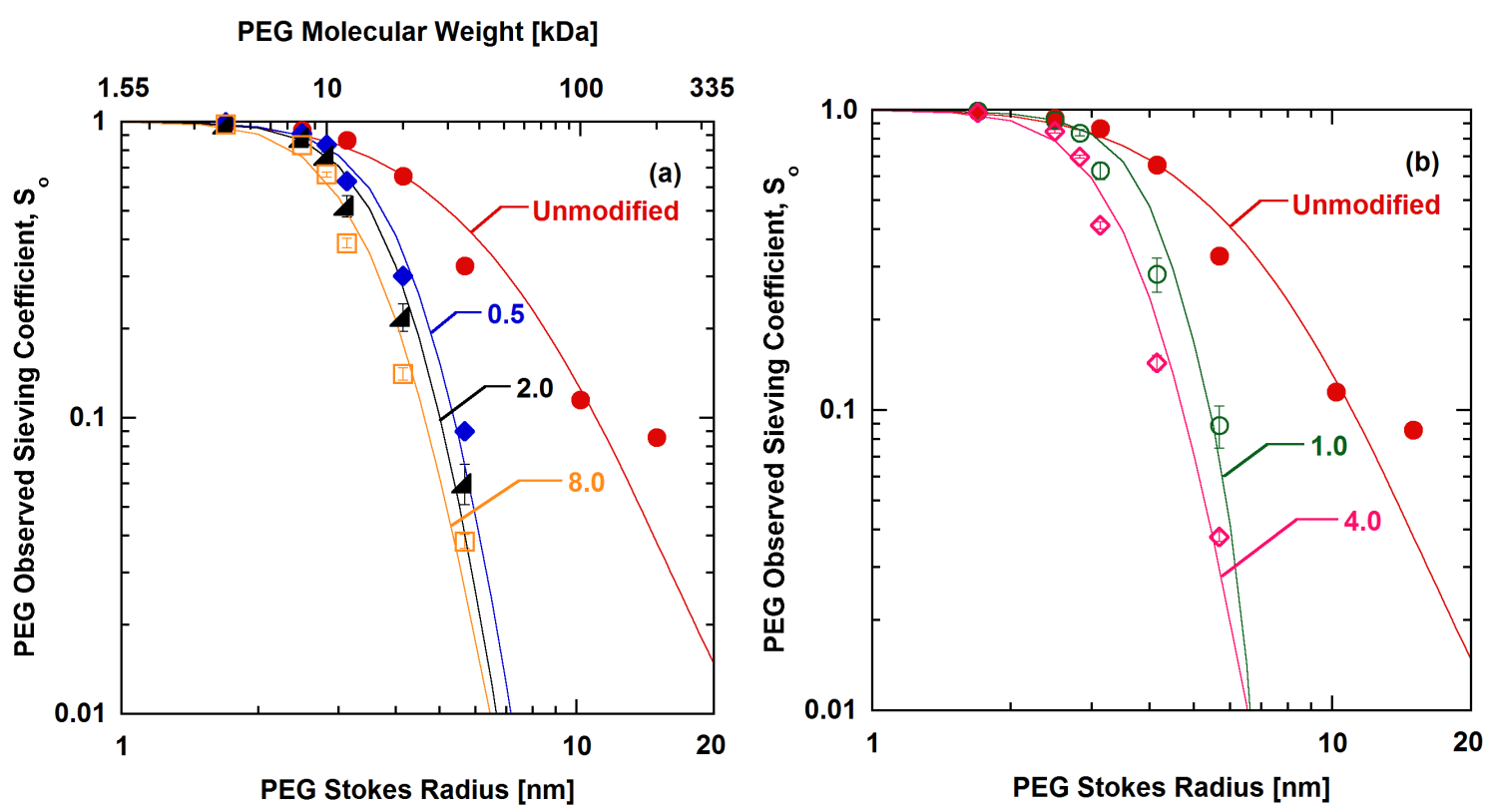

Figure 10. Effect of initial dopamine concentration on observed PEG sieving coefficient of unmodified and PDA-modified PS-20 UF membranes. Discrete data points show experimental data and solid curves show corresponding model calculations. $\varepsilon / \delta_{m}$ was used as a fitted parameter, and $k\left(r_{c}\right)$ and $J_{v}\left(r_{c}\right)$ were employed in the model calculations. The numbers in (a) and (b) represent initial dopamine concentration in $\mathrm{mg} / \mathrm{mL}$. A deposition time of 60 minutes was used. 

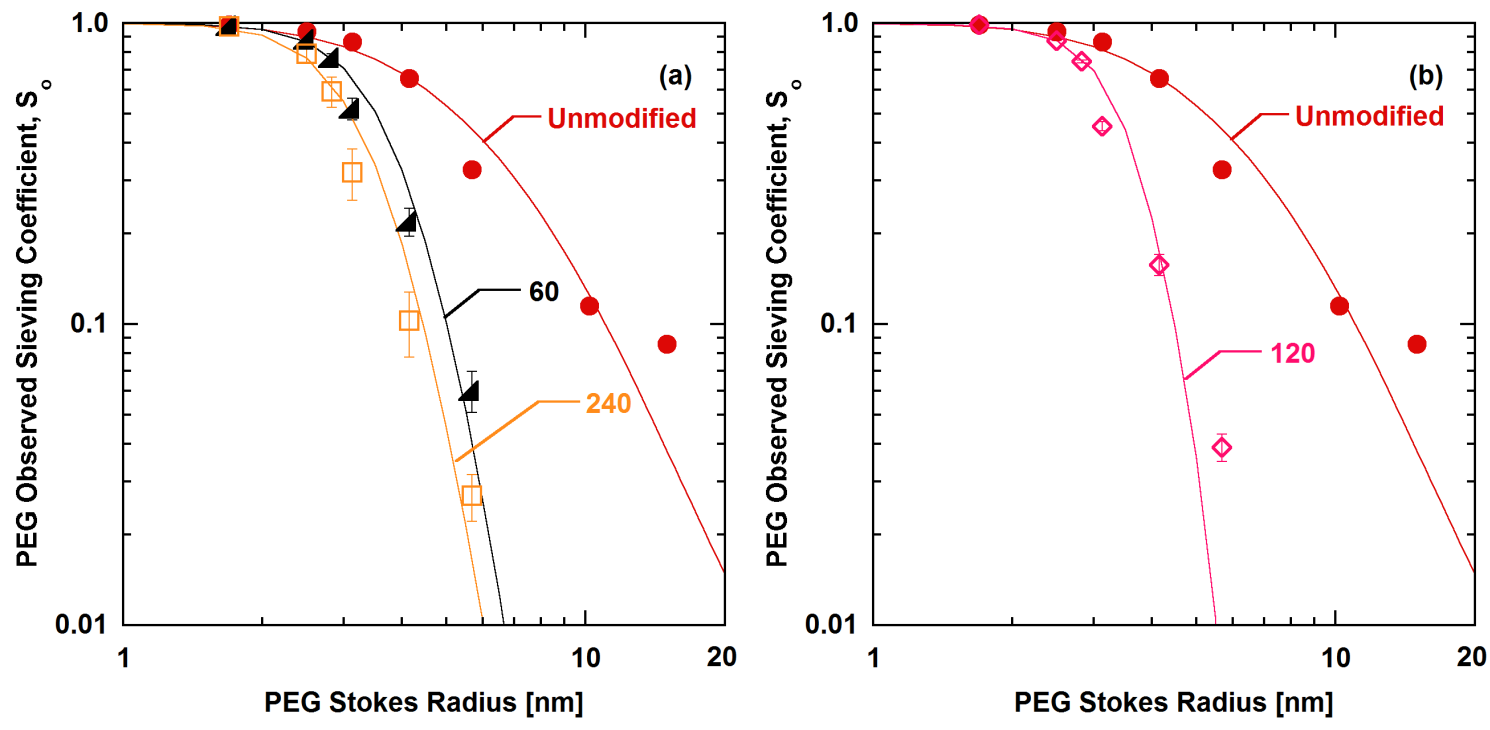

Figure 11. Effect of PDA deposition time on observed PEG sieving coefficient of unmodified and PDA-modified PS-20 UF membranes. Discrete data points show experimental data and solid curves show corresponding model calculations. $\varepsilon / \delta_{m}$ was used as a fitted parameter, and $k\left(r_{c}\right)$ and $J_{v}\left(r_{c}\right)$ were employed in the model calculations. The numbers in (a) and (b) represent PDA deposition time in minutes. An initial dopamine concentration of $2 \mathrm{mg} / \mathrm{mL}$ was used.

Figure 12 presents best fit values of $\bar{r}$ and $\sigma$ for membranes modified with PDA at various conditions. These $\bar{r}$ and $\sigma$ values represent the arithmetic (not geometric) mean and standard deviation of the membrane pore radius, respectively [27]. The uncertainties in $\bar{r}$ were estimated by varying $\bar{r}$ about its minimum $\chi^{2}$ to increase $\chi^{2}$ by 1 as explained in Bevington and Robinson [37]. Uncertainties in $\bar{r}$ calculated in this manner were less than $0.1 \mathrm{~nm}$, so they are not apparent in Figure 12. The best fit values of $\bar{r}$ and $\sigma / \bar{r}$ for unmodified and PDA-modified membranes are also tabulated in Table S.3 and Table S.4 in the supplementary information.

All PDA modification conditions led to an increase in membrane mean pore radius relative to that of unmodified membranes. At low initial dopamine concentrations (i.e., $\leq 1$ $\mathrm{mg} / \mathrm{mL}$ ), $\bar{r}$ increased with increasing initial dopamine concentration (cf., Figure 12(a)). Similarly, at short deposition times (i.e., $\leq 120$ minutes), $\bar{r}$ increased as the membranes were coated with PDA for longer times (cf., Figure 12(b)). An increase in mean pore radius with 
increasing initial dopamine concentration or deposition time is consistent with blockage of the smallest pores due to PDA deposition. Such low concentrations or short deposition times may not coat bigger pores sufficiently to significantly reduce their pore sizes, resulting in an overall increase in mean pore radius, basically shifting the pore size distribution to higher average pore sizes. Plots of the pore size distribution from the model reflect this trend (cf., Figure S.4 and Figure S.5 in the supplementary information). This increase in mean pore radius might also be influenced by membrane pore wetting due to PDA modification as reported in other studies [81].
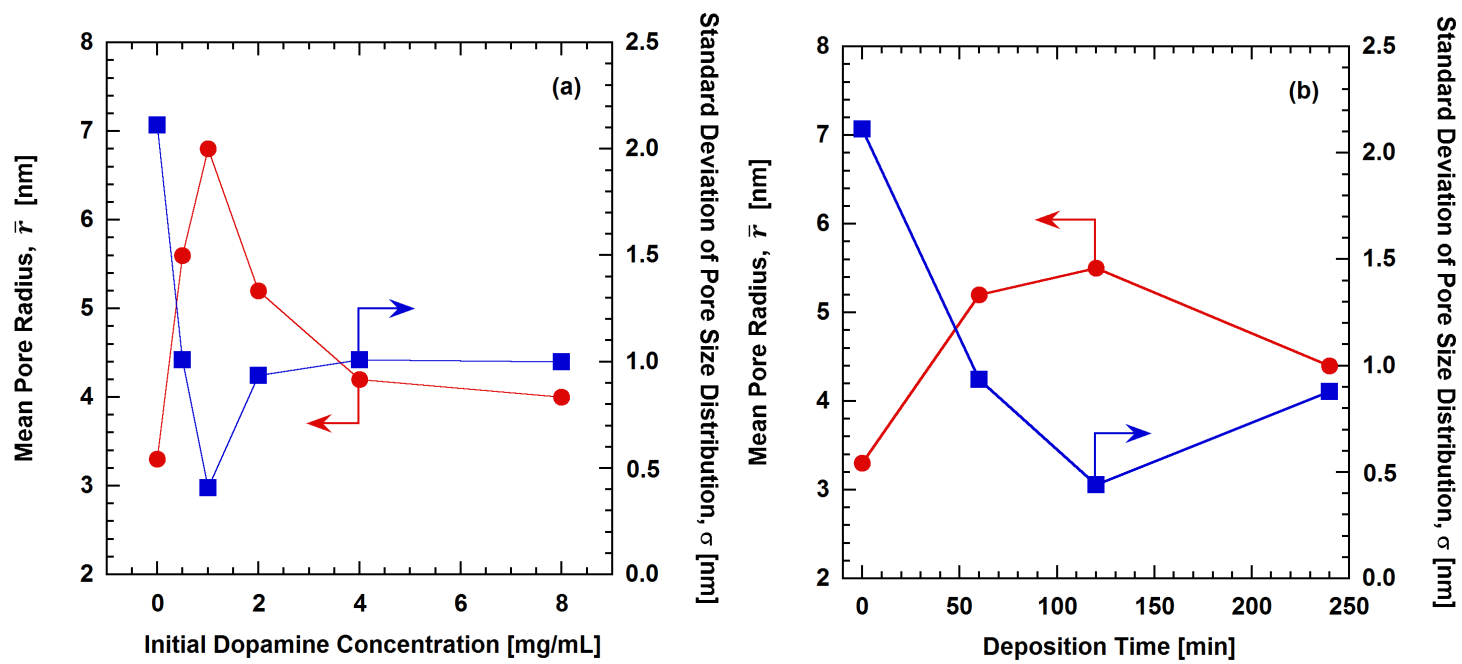

Figure 12. Effect of PDA deposition conditions on mean pore radius $(\bar{r})$ and standard deviation $(\sigma)$ of pore size distribution of PS-20 UF membranes modified with PDA at various: (a) initial dopamine concentrations and (b) deposition times. $\varepsilon / \delta_{m}$ was used as a fitted parameter, and $k\left(r_{c}\right)$ and $J_{v}\left(r_{c}\right)$ were employed in the model calculations. A deposition time of 60 minutes was used in (a), and an initial dopamine concentration of $2 \mathrm{mg} / \mathrm{mL}$ was used in (b).

In contrast, at higher initial dopamine concentrations (i.e., > $1 \mathrm{mg} / \mathrm{mL}$ ) and longer deposition times (i.e., > 120 minutes), $\bar{r}$ decreased with increasing initial dopamine concentration or increasing deposition time. At these more aggressive coating conditions, the PDA coating presumably blocked small pores and also reduced the size of large pores, decreasing the average pore radius (cf., Figure S.4 and Figure S.5). At the highest initial 
dopamine concentration (i.e., $8 \mathrm{mg} / \mathrm{mL}$ ) or longest deposition time (i.e., 240 minutes), the mean pore radius was still somewhat higher than that of the unmodified membranes. In these cases, the size reduction of large pores and small pore blockage appear to contribute to changes in the mean pore size of PDA-modified membranes, resulting in only modest increases in $\bar{r}$ from that of the unmodified membranes. The mean pore radii of unmodified and PDA-modified membranes were compared to their nominal pore radii, which were determined from MWCO experiments. This comparison is presented in Table S.3 and Table S.4, and a detailed discussion regarding the nominal and mean pore radii comparison is included in the supplementary information.

From Figure 12, $\sigma$ of membranes modified with PDA at all deposition conditions decreased relative to that of unmodified membranes. This finding is consistent with the qualitative reduction in pore size distribution inferred from the enhanced steepness of the PEG rejection curves due to PDA coating (cf., Figures 4, 5, S.4, and S.5). The PDA coating appears to reduce the size of the largest pores and block the smallest pores, which narrows the pore size distribution, leading to lower $\sigma$ values. At initial dopamine concentrations lower than $1 \mathrm{mg} / \mathrm{mL}$ or deposition times shorter than 120 minutes, $\sigma$ decreased with increasing initial dopamine concentration or deposition time, and reached minimum values. The $\sigma$ value increased and approached a plateau at higher initial dopamine concentrations (i.e., $>1 \mathrm{mg} / \mathrm{mL}$ ). Similarly, the $\sigma$ value did not decrease further at longer deposition times (i.e., > 120 minutes), but instead increased. Perhaps there were a limited number of small pores that could be completely blocked by PDA coating, resulting in minimum $\sigma$ values of the pore size distribution of PDA-modified membranes. Extensive PDA modifications at high initial dopamine concentrations or long coating times might further decrease the overall pore sizes, leading to increased number of small pores (i.e., converting larger pores to small pores due to coating) and broader pore size distribution. 
As discussed earlier, several correlations relating PEG Stokes radius to PEG molecular weight, such that similar to Equation (14), have been reported in the literature [34, 45, 68]. The correlation used in the model calculations can influence the values of $\bar{r}$ and $\sigma$, but it has no influence on the relative trends in these parameters among various PDA coating conditions. Thus, the reported fitted parameter values should not be taken to represent absolute values, given the approximations inherent in both the modeling and the PEG molecule size estimations.

Figure 13 presents the influence of initial dopamine concentration (Figure 13(a)) and deposition time (Figure 13(b)) on $\varepsilon / \delta_{m}$ estimated from the model calculations. The values of $\varepsilon / \delta_{m}$ of unmodified and PDA-modified membranes are also tabulated in Table S.3 and Table S.4 in the supplementary information. Changes in $\varepsilon / \delta_{m}$ describe changes in membrane porosity, tortuosity, and selective layer thickness, all of which could influence water and solute transport through membranes. From Figure 13(a), $\varepsilon / \delta_{m}$ of PDA-modified membranes tended to increase with increasing dopamine concentration initially, but it reached a plateau as dopamine concentration was increased above $4 \mathrm{mg} / \mathrm{mL}$. Speculatively, the PDA coating inside the pores may open pores that may have been initially inaccessible due to wettability issues by increasing the hydrophilicity of the pore walls, which would increase membrane porosity [81]. The plateau in $\varepsilon / \delta_{m}$ values could exist because all accessible pores had been opened. Although the PDA coating might increase membrane porosity in some cases, the pure water permeance of all PDAmodified membranes decreased relative to that of unmodified membranes (cf., Figure 3), suggesting that the pore size and distribution changes discussed above were responsible for the pure water permeance decrease. Any potential increase in porosity from pore opening in this study has a very minor influence on changes in pure water permeance relative to that caused by pore size and distribution changes. 

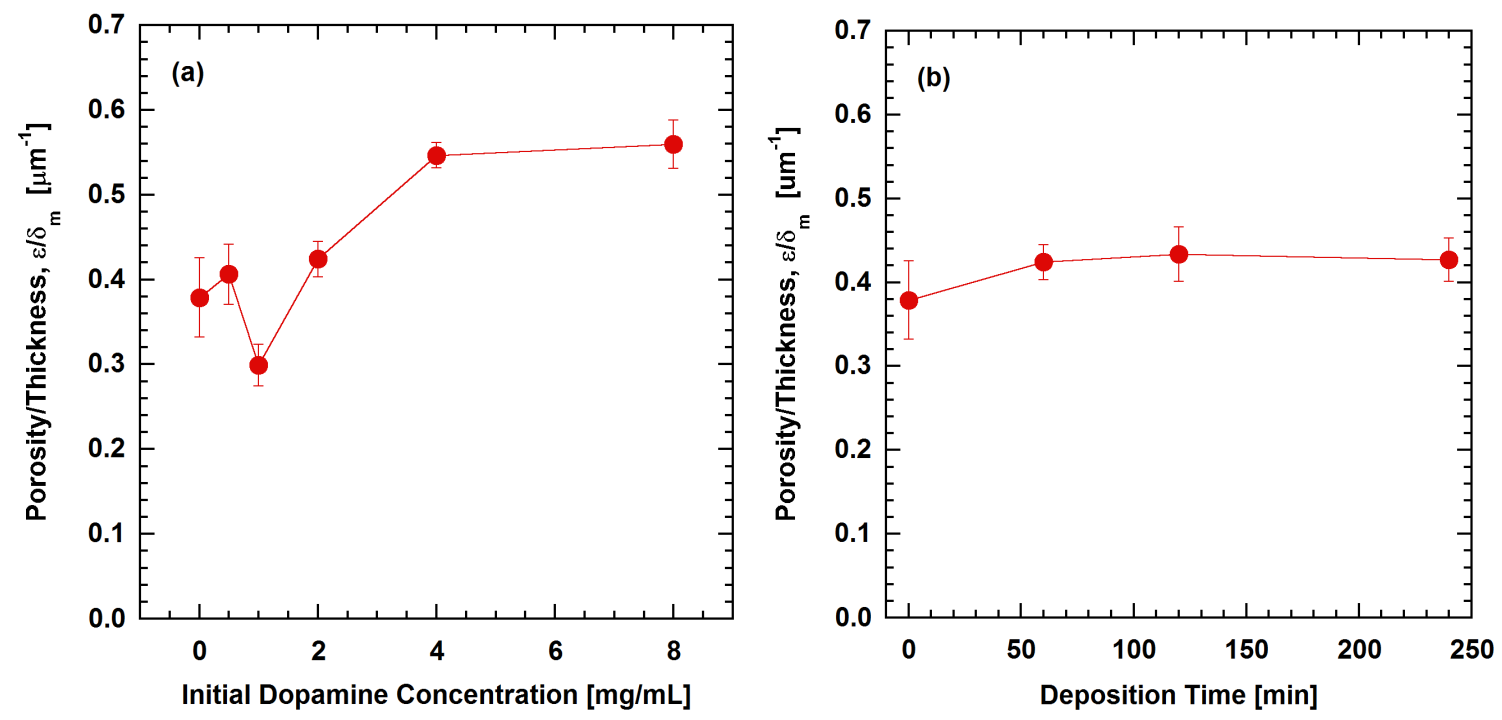

Figure 13. Effect of PDA deposition conditions on porosity to thickness ratio, $\varepsilon / \delta_{m}$, of PS-20 UF membranes modified with PDA at various: (a) initial dopamine concentrations and (b) deposition times. $\varepsilon / \delta_{m}$ was used as a fitted parameter, and $k\left(r_{c}\right)$ and $J_{v}\left(r_{c}\right)$ were employed in the model calculations. A deposition time of 60 minutes was used in (a), and an initial dopamine concentration of $2 \mathrm{mg} / \mathrm{mL}$ was used in (b).

On the other hand, from Figure 13(b), $\varepsilon / \delta_{m}$ did not significantly change when the membranes were modified with PDA for longer deposition times. Another hypothesis is that the PDA modification did not significantly influence $\varepsilon / \delta_{m}$ values. In other studies, $\varepsilon / \delta_{m}$ was chosen to be a constant value for modelling solute and solvent transport through different UF membranes [24]. Although Figure 13 shows some variation in $\varepsilon / \delta_{m}$ values at different PDA modification conditions, most of the $\varepsilon / \delta_{m}$ values were close to an average value of $0.4 \mu \mathrm{m}^{-1}$. Thus, we also modeled the membrane pore size distribution (i.e., $\bar{r}$ and $\sigma$ parameters) using a constant $\varepsilon / \delta_{m}$ value of $0.4 \mu \mathrm{m}^{-1}$. For membranes modified with PDA at each modification condition, the Hagen-Poiseuille equation (cf., Equation (1)) was used to correlate $\bar{r}$ and $\sigma$ values to achieve calculated $\bar{L}_{p}$ values equal to experimental pure water permeance values. The $\bar{r}$ and corresponding $\sigma$ values were varied (keeping $\varepsilon / \delta_{m}$ fixed), and the calculated $S_{o}$ values were computed using the hindered solute transport model (cf., Equations (9), (10), (12), and (18)) and stagnant film model (cf., Equation (21)) as explained earlier. The best fit $\bar{r}$ and $\sigma$ values for 
each membrane were determined by minimizing the $\chi^{2}$ between the modeled and experimental $S_{o}$ data.

The best fit $\bar{r}$ and $\sigma$ values from the model calculations using a fixed value of $\varepsilon / \delta_{m}(0.4$ $\mu \mathrm{m}^{-1}$ ) are presented in Figure S.2 in the supplementary information. The influence of initial dopamine concentration or PDA deposition time on these $\bar{r}$ and $\sigma$ values remained qualitatively similar to that reported in Figure 12.

\section{CONCLUSIONS}

PDA was deposited from aqueous solution onto PSf flat dense films and PS-20 UF membranes. As initial dopamine coating solution concentration or deposition time increased, the PDA surface coating thickness increased, and pure water permeance of PDA-modified PSf UF membranes decreased. MWCO, used to determine nominal pore size of the membranes, decreased with increasing initial dopamine concentration or longer deposition time. The decrease in MWCO was consistent with PDA coating inside the membrane pores, and the coating reduced the membrane nominal pore size. In addition, PDA modification led to a tradeoff in hydraulic permeability and selectivity. A hindered solute transport model was used to characterize more completely the influence of PDA deposition conditions on mean pore size and pore size distribution, as well as the ratio of porosity to selective layer thickness of the membranes. When the membranes were coated at low initial dopamine concentrations or short deposition times, the mean pore radius increased relative to that of the unmodified membranes, possibly due to blocking of small pores by PDA coating. At higher initial dopamine coating solution concentrations or longer deposition times, the mean pore size of PDA-modified membranes was somewhat higher than that of unmodified membranes. Perhaps large pores were coated sufficiently that the sizes of large pores were reduced. With contributions from the reduction in large pore sizes and blockage of small pores, there was only a moderate change in the mean pore radius of membranes modified extensively (i.e., at high dopamine concentration or long 
deposition time). The pore size distribution of all PDA-modified membranes was narrower than that of the unmodified membranes.

\section{LIST OF SYMBOLS}

a Solute or particle radius (m)

A Effective membrane filtration area $\left(\mathrm{m}^{2}\right)$

$b \quad$ Membrane radius determined from effective membrane filtration area (m)

$C_{b} \quad$ Bulk feed solute concentration $(\mathrm{mg} / \mathrm{L})$

$C_{f} \quad$ Filtrate solute concentration $(\mathrm{mg} / \mathrm{L})$

$C_{m} \quad$ Solute concentration at the membrane surface on feed side $(\mathrm{mg} / \mathrm{L})$

$D_{\infty} \quad$ PEG diffusion coefficient in infinite dilute solution $\left(\mathrm{m}^{2} / \mathrm{s}\right)$

$\bar{J}_{p w} \quad$ Average pure water flux (m/s)

$\bar{J}_{v} \quad$ Average permeate flux from solute filtration test in the stirred cell $(\mathrm{m} / \mathrm{s})$

$J_{v}\left(r_{c}\right) \quad$ Local permeate flux from solute filtration test at any radial position $r_{c}$ in the stirred cell $(\mathrm{m} / \mathrm{s})$

$K_{c} \quad$ Hindrance factor for solute convection

$K_{d} \quad$ Hindrance factor for solute diffusion

$\bar{k} \quad$ Average mass transfer coefficient $(\mathrm{m} / \mathrm{s})$

$k\left(r_{c}\right) \quad$ Local mass transfer coefficient at any radial position $r_{c}$ in the stirred cell $(\mathrm{m} / \mathrm{s})$

$\bar{L}_{p} \quad$ Average membrane pure water permeance or hydraulic permeability $(\mathrm{m} /(\mathrm{s} \cdot \mathrm{Pa}))$

$m \quad$ Permeate mass of pure water $(\mathrm{kg})$

$M \quad$ PEG molecular weight (g/mol)

$n_{0} \quad$ Total number of pores per unit membrane area

$n(r) \quad$ Total number of pores of radius $r$ per unit membrane area

$P e_{m} \quad$ Peclet number inside the membrane pores 
$P_{\text {feed }}\left(r_{c}\right) \quad$ Applied feed pressure at any radial position $r_{c}$ in the stirred cell at the membrane surface $\left(\mathrm{kg} /\left(\mathrm{m} \cdot \mathrm{s}^{2}\right)\right)$

$P_{f} \quad$ Filtrate pressure $\left(\mathrm{kg} /\left(\mathrm{m} \cdot \mathrm{s}^{2}\right)\right)$

$P_{o} \quad$ Applied feed pressure at the central axis of the stirred cell at the membrane surface $\left(\mathrm{kg} /\left(\mathrm{m} \cdot \mathrm{s}^{2}\right)\right)$

$r \quad$ Membrane pore radius (m)

$\bar{r} \quad$ Membrane mean pore radius (m)

$r_{c} \quad$ Radial position from the center of the stirred cell (m)

$R_{a} \quad$ Actual membrane retention coefficient

$R_{o} \quad$ Observed membrane retention coefficient

Re Reynolds number

$S_{a} \quad$ Actual membrane sieving coefficient

$S_{o} \quad$ Observed membrane sieving coefficient

$\bar{S}_{a} \quad$ Averaged actual membrane sieving coefficient over all pore sizes (based on log normal pore size distribution)

$S_{\infty} \quad$ Asymptotic sieving coefficient

Sc $\quad$ Schmidt number

$t \quad$ Pure water filtration time (s)

$T M P_{\text {local }}\left(r_{c}\right)$ Local transmembrane pressure at any radial position $r_{c}$ in the stirred cell $\left(\mathrm{kg} /\left(\mathrm{m} \cdot \mathrm{s}^{2}\right)\right)$

$T M P_{n} \quad$ Nominal measured (average) transmembrane pressure (pressure difference between feed and permeate side of the membrane) $\left(\mathrm{kg} /\left(\mathrm{m} \cdot \mathrm{s}^{2}\right)\right)$

$z \quad$ Axial position away from the feed surface of the membrane (m)

\subsection{Greek Symbols}

$\alpha \quad$ Separation factor

$\alpha_{\text {stir }} \quad$ Constant based on filtration device geometry for $\bar{k}$ or $k\left(r_{c}\right)$ determination 


$\begin{array}{ll}\chi^{2} & \text { Chi-squared goodness-of-fit parameter } \\ \delta_{c} & \text { Concentration boundary layer thickness }(\mathrm{m}) \\ \delta_{m} & \text { Membrane selective layer thickness }(\mathrm{m}) \\ \varepsilon & \text { Porosity of membrane selective layer } \\ \mu & \text { Dynamic viscosity of solvent }(\mathrm{kg} /(\mathrm{m} \cdot \mathrm{s})) \\ v & \text { Kinematic viscosity of solvent }\left(\mathrm{m}^{2} / \mathrm{s}\right) \\ \omega & \text { Stirring speed in the stirred filtration cell (radians/s) } \\ \phi & \text { Equilibrium partition coefficient } \\ \rho & \text { Density of solvent }\left(\mathrm{kg} / \mathrm{m}^{3}\right) \\ \sigma & \text { Standard deviation of log-normal pore size distribution }(\mathrm{m})\end{array}$

\section{ACKNOWLEDGEMENTS}

The authors gratefully acknowledge financial support from the National Science Foundation Science and Technology Center for Layered Polymeric Systems (DMR-0423914) and the National Science Foundation grant number CBET-1160069 and CBET 1403670. This work was also partially supported by the International Institute for Carbon-Neutral Energy Research (WPI-I2CNER), Kyushu University of World Premier International Research Center Initiative (WPI), MEXT, Japan.

\section{REFERENCES}

[1] R.W. Baker, Membrane Technology and Applications, 2nd ed., John Wiley \& Sons Ltd., West Sussex, England, 2004.

[2] M. Cheryan, Ultrafiltration and Microfiltration Handbook, Technomic Publishing Co., Inc., Lancaster, PA, 1998.

[3] M.C. Porter, Handbook of Industrial Membrane Technology, Noyes Publications, Park Ridge, NJ, 1990.

[4] D.J. Miller, X. Huang, H. Li, S. Kasemset, A. Lee, D. Agnihotri, T. Hayes, D.R. Paul, B.D. Freeman, Fouling-resistant membranes for the treatment of flowback water from hydraulic shale fracturing: A pilot study, Journal of Membrane Science 437 (2013) 265275. 
[5] T.C. Arnot, R.W. Field, A.B. Koltuniewicz, Cross-flow and dead-end microfiltration of oily-water emulsions Part II. Mechanisms and modelling of flux decline, Journal of Membrane Science 169 (2000) 1-15.

[6] A.B. Koltuniewicz, R.W. Field, Process factors during removal of oil-in-water emulsions with cross-flow microfiltration, Desalination 105 (1996) 79-89.

[7] G. Belfort, R.H. Davis, A.L. Zydney, The behavior of suspensions and macromolecular solutions in crossflow microfiltration, Journal of Membrane Science 96 (1994) 1-58.

[8] L.J. Zeman, A.L. Zydney, Microfiltration and Ultrafiltration: Principles and Applications, Marcel Dekker, Inc., New York, NY, 1996.

[9] P. Le-Clech, V. Chen, A.G. Fane, Fouling in membrane bioreactors used in wastewater treatment, Journal of Membrane Science 284 (2006) 17-53.

[10] M.F.A. Goosen, S.S. Sablani, H. Al-Hinai, S. Al-Obeidani, R. Al-Belushi, D. Jackson, Fouling of reverse osmosis and ultrafiltration membranes: A critical review, Separation Science and Technology 39 (2004) 2261-2297.

[11] D. Rana, T. Matsuura, Surface modifications for antifouling membranes, Chemical Reviews 110 (2010) 2448-2471.

[12] B.D. Freeman, I. Pinnau, Gas and Liquid Separations Using Membranes: An Overview, in: ACS Symposium Series 876 (Advanced Materials for Membrane Separations), American Chemical Society, Washington, DC, 2004, pp. 1-23.

[13] M. Elimelech, W.A. Phillip, The future of seawater desalination: Energy, technology, and the environment, Science 333 (2011) 712-717.

[14] H. Lee, S.M. Dellatore, W.M. Miller, P.B. Messersmith, Mussel-inspired surface chemistry for multifunctional coatings, Science 318 (2007) 426-430.

[15] D.J. Miller, D.R. Paul, B.D. Freeman, An improved method for surface modification of porous water purification membranes, Polymer 55 (2014) 1375-1383.

[16] D.J. Miller, S. Kasemset, L. Wang, D.R. Paul, B.D. Freeman, Constant flux crossflow filtration evaluation of surface-modified fouling-resistant membranes, Journal of Membrane Science 452 (2014) 171-183.

[17] B.D. McCloskey, H.B. Park, H. Ju, B.W. Rowe, D.J. Miller, B.D. Freeman, A bioinspired fouling-resistant surface modification for water purification membranes, Journal of Membrane Science 413-414 (2012) 82-90.

[18] B.D. McCloskey, H.B. Park, H. Ju, B.W. Rowe, D.J. Miller, B.J. Chun, K. Kin, B.D. Freeman, Influence of polydopamine deposition conditions on pure water flux and foulant adhesion resistance of reverse osmosis, ultrafiltration, and microfiltration membranes, Polymer 51 (2010) 3472-3485.

[19] C. Cheng, S. Li, W. Zhao, Q. Wei, S. Nie, S. Sun, C. Zhao, The hydrodynamic permeability and surface property of polyethersulfone ultrafiltration membranes with 
mussel-inspired polydopamine coatings, Journal of Membrane Science 417-418 (2012) 228-236.

[20] J. Jiang, L. Zhu, X. Li, Y. Xu, B. Zhu, Surface modification of PE porous membranes based on the strong adhesion of polydopamine and covalent immobilization of heparin, Journal of Membrane Science 364 (2010) 194-202.

[21] Z. Xi, Y. Xu, L. Zhu, Y. Wang, B. Zhu, A facile method of surface modification for hydrophobic polymer membranes based on the adhesive behavior of poly(DOPA) and poly(dopamine), Journal of Membrane Science 327 (2009) 244-253.

[22] L. Zhu, J. Yu, Y. Xu, Z. Xi, B. Zhu, Surface modification of PVDF porous membranes via poly(DOPA) coating and heparin immobilization, Colloids and Surfaces B: Biointerfaces 69 (2009) 152-155.

[23] J.E. Flinn, Membrane Science and Technology: Industrial, Biological, and Waste Treatment Processes, Plenum Press, New York, NY, 1970.

[24] A. Mehta, A.L. Zydney, Permeability and selectivity analysis for ultrafiltration membranes, Journal of Membrane Science 249 (2005) 245-249.

[25] S. Mochizuki, A.L. Zydney, Theoretical analysis of pore size distribution effects on membrane transport, Journal of Membrane Science 82 (1993) 211-227.

[26] B.E. Poling, G.H. Thomson, D.G. Friend, R.L. Rowley, W.V. Wilding, Section 2 Physical and Chemical Data, in: D.W. Green, R.H. Perry (Eds.) Perry's Chemical Engineer's Handbook, 8th ed., McGraw-Hill, New York, 2008.

[27] A.L. Zydney, P. Aimar, M. Meirele, J.M. Pimbley, G. Belfort, Use of the log-normal probability density function to analyze membrane pore size distributions: Functional forms and discrepancies, Journal of Membrane Science 91 (1994) 293-298.

[28] A.L. Zydney, A. Xenopoulos, Improving dextran tests for ultrafiltration membranes: Effect of device format, Journal of membrane Science 291 (2007) 180-190.

[29] M. Mulder, Basic Principles of Membrane Technology, Kluwer Academic Publishers, Dordrecht, The Netherlands, 1991.

[30] W.S. Opong, A.L. Zydney, Diffusive and convective protein transport through asymmetric membranes, AIChE Journal 37 (1991) 1497-1510.

[31] C. Causserand, S. Rouaix, A. Akbari, P. Aimar, Improvement of a method for the characterization of ultrafiltration membranes by measurements of tracers retention, Journal of Membrane Science 238 (2004) 177-190.

[32] J. Shao, R.E. Baltus, Hindered diffusion of dextran and polyethylene glycol in porous membranes, AIChE Journal 46 (2000) 1149-1156.

[33] C.Y. Chang, W.T. Tsai, C.H. Ing, C.F. Chang, Adsorption of polyethylene glycol (PEG) from aqueous solution onto hydrophobic zeolite, Journal of Colloid and Interface Science 260 (2003) 273-279. 
[34] S. Singh, K.C. Khulbe, T. Matsuura, P. Ramamurthy, Membrane characterization by solute transport and atomic force microscopy, Journal of Membrane Science 142 (1998) $111-127$.

[35] S.T. Johnston, K.A. Smith, W.M. Deen, Concentration polarization in stirred ultrafiltration cells, AIChE Journal 47 (2001) 1115-1125.

[36] K.A. Smith, C.K. Colton, E.W. Merrill, L.B. Evans, Convective transport in a batch dialyzer: Determination of true membrane permeability from a single measurement, AIChE Symposium Series 64 (1968) 45-58.

[37] P.R. Bevington, D.K. Robinson, Data Reduction and Error Analysis for the Physical Sciences, 3rd ed., The McGraw-Hill Companies, Inc., New York, NY, 2003.

[38] D.J. Miller, S. Kasemset, D.R. Paul, B.D. Freeman, Comparison of membrane fouling at constant flux and constant transmembrane pressure conditions, Journal of Membrane Science 454 (2014) 505-515.

[39] Y. Huang, D.R. Paul, Experimental methods for tracking physical aging of thin glassy polymer films by gas permeation, Journal of Membrane Science 244 (2004) 167-178.

[40] CompleteEASE ${ }^{\mathrm{TM}}$ Data Analysis Manual, J.A. Woollam Co. Inc., Lincoln, NE, 2011.

[41] A.C. Sagle, E.M. Van Wagner, H. Ju, B.D. McCloskey, B.D. Freeman, M.M. Sharma, PEG-coated reverse osmosis membranes: Desalination properties and fouling resistance, Journal of Membrane Science 340 (2009) 92-108.

[42] S. Kasemset, A. Lee, D.J. Miller, B.D. Freeman, M.M. Sharma, Effect of polydopamine deposition conditions on fouling resistance, physical properties, and permeation properties of reverse osmosis membranes in oil/water separation, Journal of Membrane Science 425-426 (2013) 208-216.

[43] ASTM Standard E1343 - 90, 1996 (2001), "Standard Test Method for Molecular Weight Cutoff Evaluation of Flat Sheet Ultrafiltration Membranes," ASTM International, West Conshohocken, PA, 2001, DOI: 10.1520/E1343-90R01, www.astm.org.

[44] R. Rohani, M. Hyland, D. Patterson, A refined one-filtration method for aqueous based nanofiltration and ultrafiltration membrane molecular weight cut-off determination using polyethylene glycols, Journal of Membrane Science 382 (2011) 278-290.

[45] C.M. Tam, A.Y. Tremblay, Membrane pore characterization - comparison between single and multicomponent solute probe techniques, Journal of Membrane Science 57 (1991) 271-287.

[46] S.P. Nunes, M.L. Sforça, K.-V. Peinemann, Dense hydrophilic composite membranes for ultrafiltration, Journal of Membrane Science 106 (1995) 49-56.

[47] Y.H. Wu, Y.L. Liu, Y. Chang, A. Higuchi, B.D. Freeman, Effect of UV intensity on structure, water sorption, and transport properties of crosslinked N-vinyl-2pyrrolidone/N,N'-methylenebisacrylamide films, Journal of Membrane Science 348 (2010) 47-55. 
[48] R.A. Zangmeister, T.A. Morris, M.J. Tarlov, Characterization of polydopamine thin films deposited at short times by autoxidation of dopamine, Langmuir 29 (2013) 8619-8628.

[49] V. Ball, D.D. Frari, V. Toniazzo, D. Ruch, Kinetics of polydopamine film deposition as a function of $\mathrm{pH}$ and dopamine concentration: Insights in the polydopamine deposition mechanism, Journal of Colloid and Interface Science 386 (2012) 366-372.

[50] J. Jiang, L. Zhu, L. Zhu, B. Zhu, Y. Xu, Surface characteristics of a self-polymerized dopamine coating deposited on hydrophobic polymer films, Langmuir 27 (2011) 1418014187.

[51] K. Kang, I.S. Choi, Y. Nam, A biofunctionalization scheme for neural interfaces using polydopamine polymer, Biomaterials 32 (2011) 6374-6380.

[52] J. Ou, J. Wang, S. Liu, J. Zhou, S. Ren, S. Yang, Microtribological and electrochemical corrosion behaviors of polydopamine coating on APTS-SAM modified Si substrate, Applied Surface Science 256 (2009) 894-899.

[53] F. Pan, H. Jia, S. Qiao, Z. Jiang, J. Wang, B. Wang, Y. Zhong, Bioinspired fabrication of high performance composite membranes with ultrathin defect-free skin layer, Journal of Membrane Science 341 (2009) 279-285.

[54] B. Li, W. Liu, Z. Jiang, X. Dong, B. Wang, Y. Zhong, Ultrathin and stable active layer of dense composite membrane enabled by poly(dopamine), Langmuir 25 (2009) 7368-7374.

[55] F. Bernsmann, A. Ponche, C. Ringwald, J. Hemmerle, J. Raya, B. Bechinger, J.-C. Voegel, P. Schaaf, V. Ball, Characterization of dopamine - melanin growth on silicon oxide, Journal of Physical Chemistry 113 (2009) 8234-8242.

[56] Y. Liu, K. Ai, L. Lu, Polydopamine and its derivative materials: Synthesis and promising applications in energy, environmental, and biomedical fields, Chemical Reviews 114 (2014) 5057-5115.

[57] N.F. Della Vecchia, R. Avolio, M. Alfè, M.E. Errico, A. Napolitano, M. d’Ischia, Building-block diversity in polydopamine underpins a multifunctional eumelanin-type platform tunable through a quinone control point, Advanced Functional Materials 23 (2013) 1331-1340.

[58] D.R. Dreyer, D.J. Miller, B.D. Freeman, D.R. Paul, C.W. Bielawski, Perspectives on poly(dopamine), Chemical Science 4 (2013) 3796-3802.

[59] H.W. Kim, B.D. McCloskey, T.H. Choi, C. Lee, M.J. Kim, B.D. Freeman, H.B. Park, Oxygen concentration control of dopamine-induced high uniformity surface coating chemistry, Applied Materials and Interfaces 5 (2013) 233-238.

[60] D.R. Dreyer, D.J. Miller, B.D. Freeman, D.R. Paul, C.W. Bielawski, Elucidating the structure of poly(dopamine), Langmuir 28 (2012) 6428-6435.

[61] C. Causserand, P. Aimar, Characterization of Filtration Membranes, in: E. Drioli, L. Giorno (Eds.) Comprehensive Membrane Science and Engineering, 1st ed., Elsevier, Kidlington, United Kingdom, 2010. 
[62] W.S.W. Ho, K.K. Sirkar, Membrane Handbook, Van Nostrand Reinhold, New York, NY, 1992.

[63] S. Platt, M. Mauramo, S. Butylina, M. Nystrom, Retention of pegs in cross-flow ultrafiltration through membranes, Desalination 149 (2002) 417-422.

[64] P. Aimar, M. Meireles, V. Sanchez, A contribution to the translation of retention curves into pore size distributions for sieving membranes, Journal of Membrane Science 54 (1990) 321-338.

[65] L. Zeman, M. Wales, Polymer Solute Rejection by Ultrafiltration Membranes, in: A.F. Turbak (Ed.) ACS Symposium Series 154 (Synthetic Membranes: Volume II Hyper- and Ultrafiltration Uses), American Chemical Society, Washington, DC, 1981, pp. 411-434.

[66] A.S. Michaels, Analysis and prediction of sieving curves for ultrafiltration membranes: A universal correlation?, Separation Science and Technology 15 (1980) 1305-1322.

[67] B. Schlichter, V. Mavrov, H. Chmiel, Comparative characterisation of different commercial UF membranes for drinking water production, Journal of Water Supply: Research and Technology-AQUA 49 (2000) 321-328.

[68] S. Gaches, Application de la Viscosimetrie a la Determination du Rayon de Giration de Macromolecules, DEA Génie des Procédés, Université Paul Sabatier, 1991.

[69] D.P. O’Shea, Nanostone Water (formerly Ultura and formerly Sepro Membranes, Inc.), Personal Communication, 2013.

[70] G. Schock, A. Miquel, R. Birkenberger, Characterization of ultrafiltration membranes: Cut-off determination by gel permeation chromatography, Journal of Membrane Science 41 (1989) 55-67.

[71] G. Trägårdh, Characterization methods for ultrafiltration membranes, Desalination 53 (1985) 25-35.

[72] P. Prádanos, J.I. Arribas, A. Hernández, Mass transfer coefficient and retention of PEGs in low pressure cross-flow ultrafiltration through asymmetric membranes, Journal of Membrane Science 99 (1995) 1-20.

[73] S. Mochizuki, A.L. Zydney, Dextran transport through asymmetric ultrafiltration membranes: Comparison with hydrodynamic models, Journal of Membrane Science 68 (1992) 21-41.

[74] X. Zheng, J. Zhang, J. Wang, X. Qi, J.M. Rosenholm, K. Cai, Polydopamine coatings in confined nanopore space: Toward improved retention and release of hydrophilic cargo, Journal of Physical Chemistry C 119 (2015) 24512-24521.

[75] N. Sun, C. Deng, Y. Li, X. Zhang, Size-exclusive magnetic graphene/mesoporous silica composites with titanium(IV)-immobilized pore walls for selective enrichment of endogenous phosphorylated peptides, Applied Materials and Interfaces 6 (2014) 11799-11804. 
[76] Y. Li, Y. Su, X. Zhao, X. He, R. Zhang, J. Zhao, X. Fan, Z. Jiang, Antifouling, high-flux nanofiltration membranes enabled by dual functional polydopamine, Applied Materials and Interfaces 6 (2014) 5548-5557.

[77] A. Nematollahzadeh, A. Shojaei, M.J. Abdekhodaie, B. Sellergren, Molecularly imprinted polydopamine nano-layer on the pore surface of porous particles for protein capture in HPLC column, Journal of Colloid and Interface Science 404 (2013) 117-126.

[78] G.M. Geise, H.B. Park, A.C. Sagle, B.D. Freeman, J.E. McGrath, Water permeability and water/salt selectivity tradeoff in polymers for desalination, Journal of Membrane Science 369 (2011) 130-138.

[79] R.W. Baker, B.T. Low, Gas separation membrane materials: A perspective, Macromolecules 47 (2014) 6999-7013.

[80] D.F. Sanders, Z.P. Smith, R. Guo, L.M. Robeson, J.E. McGrath, D.R. Paul, B.D. Freeman, Energy-efficient polymeric gas separation membranes for a sustainable future: A review, Polymer 54 (2013) 4729-4761.

[81] J.T. Arena, B.D. McCloskey, B.D. Freeman, J.R. McCutcheon, Surface modification of thin film composite membrane support layers with polydopamine: Enabling use of reverse osmosis membranes in pressure retarded osmosis, Journal of Membrane Science 375 (2011) 55-62. 